\title{
Supplementing Sulfate-Based Alginate Polysaccharide Improves Pacific White Shrimp (Litopenaeus vannamei) Fed Fishmeal Replacement with Cottonseed Protein Concentrate: Effects on Growth, Intestinal Health, and Disease Resistance
}

\author{
Guofeng Chen, ${ }^{1,2,3}$ Baoqiang Liu,, ${ }^{1,2,3}$ Jiajun Chen, ${ }^{1,2,3}$ Hongyu Liu $\mathbb{D}^{1,2,3}$ Beiping Tan ${ }^{10},{ }^{1,2,3}$ \\ Xiaohui Dong $\mathbb{D}^{1,2,3}$ Qihui Yang $\mathbb{D}^{1,2,3}$ Shuyan Chi, ${ }^{1,2,3}$ Shuang Zhang, ${ }^{1,2,3}$ and Min Yao ${ }^{4}$ \\ ${ }^{1}$ Laboratory of Aquatic Animal Nutrition and Feed, College of Fisheries, Guangdong Ocean University, Zhanjiang, \\ Guangdong, China \\ ${ }^{2}$ Aquatic Animals Precision Nutrition and High Efficiency Feed Engineering Research Center of Guangdong Province, Zhanjiang, \\ Guangdong, China \\ ${ }^{3}$ Key Laboratory of Aquatic, Livestock and Poultry Feed Science and Technology in South China, Ministry of Agriculture, Zhanjiang, \\ Guangdong 524000, China \\ ${ }^{4}$ Haixingyuan Biological Technology Co., Ltd., Qingdao, Shandong, China
}

Correspondence should be addressed to Hongyu Liu; liuhyu@gdou.edu.cn

Received 1 November 2021; Revised 15 December 2021; Accepted 29 December 2021; Published 8 February 2022

Academic Editor: Jianguang Qin

Copyright ( 2022 Guofeng Chen et al. This is an open access article distributed under the Creative Commons Attribution License, which permits unrestricted use, distribution, and reproduction in any medium, provided the original work is properly cited.

Sulfate-based alginate polysaccharide (SAP) is a novelty marine prebiotic. To investigate the beneficial effects of SAP in Pacific white shrimp (Litopenaeus vannamei) fed low-fishmeal diets, six diets (whole fishmeal group: FM; fishmeal replacement with cottonseed protein concentrate and SAP supplementary groups: SAP0, SAP1, SAP2, SAP3, and SAP4) were formulated and fed shrimp for 56 days. The results showed that SAP2 and SAP3 groups reached the best weight gain and specific growth rate $(P<0.05)$. In serum, the activities of lysozyme and acid phosphatase showed the trend of firstly increased and then decreased $(P<0.05)$. In the gut, the highest activities of trypsin, lipase, and amylase were found in SAP2 and SAP3 groups $(P<0.05)$; the histological indexes gradually improved with SAP levels increased $(P<0.05)$; sequencing of microbiota revealed that the composition and structure of microbiota have been improved, especially in the decreasing abundance of Vibrio, Pseudoalteromonas, and Candidatus Bacilloplasma at genus level. Besides, transcriptomics revealed a degree of similarity in differential gene expression patterns in shrimp; the comparison of RNA-Seq and qRT-PCR verified that SAP improved antioxidant and immunity in shrimp. The challenge revealed that SAP strengthened the resistance against Vibrio parahaemolyticus. Totally, the supplementary SAP to low-fishmeal diets improved growth, intestinal health, and disease resistance in shrimp. Based on the polynomial curve analysis of specific growth rate among SAPs groups, the optimum SAP supplementary level was $1.91 \%$.

\section{Introduction}

Pacific white shrimp (Litopenaeus vannamei) is a widely distributed omnivorous crustacean. The shrimp performs excellent traits, such as strong adaptability, rapid growth rate, and abundant nutritional value [1]. In aquatic commercial market, the shrimp obtains high economic value, which is well popular with the consumer $[2,3]$.

In recent years, aquaculture has made great progress, providing high-quality food protein for the public. However, the global fishmeal production resource is in short supply, due to the El Niño phenomenon [4], overfishing, and marine 
pollution [5]. According to the statistics conducted by FAO (Food and Agriculture Organization) [6], the global demand for fishmeal has increased year by year, yet the fishmeal production cannot meet the aquatic industry development [7]. The plant protein possesses the advantages of wide sources, multiple types, large yields, and low prices, comparing with protein sources obtained from other channels. Plant protein has broad application prospect and promotion value. In brief, utilizing plant protein to replace fishmeal is one of the solutions for sustainable aquaculture $[8,9]$.

However, the aquatic animals generally possess low tolerance to dietary plant proteins, due to the negative factors such as antinutritional factors, imbalanced essential amino acids, unreasonable fatty acid composition, and poor palatability [10]. This has led to restriction on the application of plant protein in aquafeeds. According to related studies conducted on high-level plant protein feed, Pacific white shrimp would perform reduced growth performance [11], body composition change [12], lowered digestion [13], and antioxidant obstacle [14]. In order to improve the utilization efficiency of plant protein, it is a question worth exploring that relieves the negative impact of fishmeal replacement [15]. Cottonseed protein concentrate (CPC) is a new type of dietary raw material made from cottonseed, which is made through leaching, extraction, and concentration. It has the characteristics of high protein ingredient and low antinutritional content [16]. Cottonseed protein concentrate is considered to be a protein source with application prospects in the aquaculture field. A related study found that CPC can be used as a partial alternative protein source for hybrid grouper (oEpinephelus fuscoguttatus $\times{ }^{\top} E$. lanceolatus) [17] and juvenile golden pompano (Trachinotus ovatus) [18]. However, Wan et al.[11] conducted a study in L. vannamei and found that high level of CPC replacement fishmeal would slow down the shrimp growth and disturb indexes of hemolymph and hematology.

To eliminate the negative effects of reducing fishmeal, algal polysaccharide is the potentially ameliorative modifier. With antibiotics not being recommended in aquaculture, algal polysaccharide is also an environmentally friendly feed supplementation. The seaweed polysaccharides come from enzymatically hydrolyzed marine algae using special craftsmanship. In recent years, related researchers have devoted themselves to the pharmacological study of seaweed polysaccharides, which has laid theoretical foundation for seaweed polysaccharide application in aquaculture. Moreover, the global field is rich in seaweed resources, which have a broad prospect of exploitation and application [19, 20]. Related studies have shown that algal polysaccharide possesses a variety of physiologically active functions in maintaining organism health. Chotigeat et al. [21] proved that seaweed polysaccharides can strengthen disease resistance in black tiger shrimp (Penaeus monodon). Besides, Supamattaya et al. [22] confirmed that the seaweed extract could improve immune response and health condition in Pacific white shrimp. Another study has found that three different seaweed polysaccharides both can maintain intestinal microbiota homeostasis, promoting probiotic proliferation and production of short-chain fatty acids, yet inhibiting condi- tional pathogens [23]. Wcl et al. [24] conducted a study in banana shrimp (Fenneropenaeus merguiensis) and found that dietary seaweed (Enteromorpha) polysaccharide improves growth performance involved in regulation of immune responses, intestinal histology, and microbial community. As a prebiotic and potential immunomodulator, the research and application of seaweed polysaccharides in aquatic animals are still in progress $[25,26]$. It is worth noting that the sulfate-based alginate polysaccharide (SAP) is a novel seaweed allosteric extract that fermented from brown algae, red algae, and green algae, whose sulfate anion is abundant in molecular structure. Due to the multiple biological activities, the sulfate-based alginate polysaccharide has potentially attempted prospects that needed further study in aquaculture.

In this context, it is an interesting issue to investigate SAP supplementary effects in shrimp fed reducing dietary fishmeal. The present study focused on shrimp growth performance, serum biochemical indexes, intestinal morphology, intestinal microbiota, and gut-related gene expression by virtue of transcriptome analysis. The present study provides deeper insight for dietary supplementation in low fishmeal feed, promoting the environmentally friendly development of aquaculture.

\section{Materials and Methods}

2.1. Experimental Diets. The experimental sulfate-based alginate polysaccharide (SAP) was provided by Haixingyuan Biological Technology Co., Ltd. (Qingdao, China), which was prepared by specially enzymatic hydrolysis of brown algae, red algae, and green algae. The sugar hydroxyl group of SAP contains abundant sulfuric acid groups, which is the active site of SAP. Figure 1 shows the absolute molecular configuration of SAP.

To prepare diets, fish meal, cottonseed protein concentrate, shrimp shell meal, soybean meal, corn protein flour, peanut meal, and wheat flour were used as protein sources, while fish oil and soy lecithin were used as lipid sources. Firstly, the fishmeal level of the reference group (FM) was set at $25 \%$. Based on that, $30 \%$ fishmeal protein was replaced by cottonseed protein concentrate to establish five SAP experimental groups. In the SAP experimental groups, sulfate-based alginate polysaccharide (SAP) supplementation was added at $0 \%, 1 \%, 2 \%, 3 \%$, and $4 \%$ levels, respectively. The ingredient compositions and nutrient contents of test diets are shown in Table 1; besides, the essential amino acid (EAA) profiles of test diets are shown in Table 2.

In the process of feed production, various feed materials were crushed and passed through an 80-mesh sieve, accurately weighed according to the feed formulation. The microcomponents were added by the step-by-step expansion principle and then being mixed with the bulk raw materials evenly. They were extruded with a twin-screw granulator (Huagong Electromechanical Technology Co., Ltd., Guangzhou, China) into two kinds of pellet feeds of 1.0 and $1.5 \mathrm{~mm}$. To improve the digestibility and stability of feed, the pellets were cured at $60^{\circ} \mathrm{C}$ for $30 \mathrm{~min}$, then air-dried for 48 hours, and finally stored at $-20^{\circ} \mathrm{C}$ until use. 


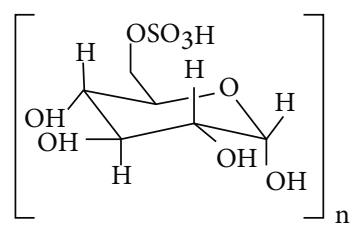

FIGURE 1: Map of absolute configuration of the molecular structure for sulfate-based alginate polysaccharide measured by infrared spectroscopy and chromatography.

2.2. Feeding Management. The culture experiment was approved by the Animal Ethics Committee of Guangdong Ocean University. The culture trial was conducted in $0.3 \mathrm{~m}^{3}$ tanks of indoor culture system at the Marine Biological Research Base of Guangdong Ocean University (Donghai Island, Zhanjiang). The experimental shrimp larvae were obtained from the Southern Base of Marine-culture Seed Project of National 863 Program (Zhanjiang, China) and temporarily reared in outdoor concrete pond for 4 weeks. Before the formal experiment, 720 shrimp larvae of uniform size, healthy physique, and active vitality were randomly selected, whose initial weight was $0.73 \pm 0.02 \mathrm{~g}$. They were randomly divided into 6 groups with 3 replicates, and 40 shrimps were farmed in each tank. The culture experiment lasted for 56 days.

During culture, the feeding amount was calculated as $8 \%-10 \%$ of body weight, which also would be adjusted according to weather, water quality, and shrimp vigor. Besides, the feeding was conducted four times in each day at 07:00, 11:00, 17:00, and 21:00, respectively. The shrimp food intake was observed after feeding for 30 to 60 minutes. The water was changed every other day at the initial stage of experiment and every day at the last stage. The water change was ranging from $1 / 3$ to $1 / 2$ of the tank. Oxygenation was continued during the culture period; thus, the dissolved oxygen concentration was higher than $6.7 \mathrm{mg} / \mathrm{L}$. The water temperature ranged from $28.4^{\circ} \mathrm{C}$ to $31.2^{\circ} \mathrm{C}$. The total alkalinity ranged from 100 to $110 \mathrm{ppm}$. The salinity fluctuation was $26 \sim 28$. The $\mathrm{pH}$ ranged from 7.8 to 8.2 . Besides, the ammonia nitrogen concentration was less than $0.03 \mathrm{mg} / \mathrm{L}$.

At the end of the feeding trial, 30 shrimps were randomly selected from each treatment for the challenge experience against Vibrio parahaemolyticus. The resource of $V$. parahaemolyticus was obtained from the Key Laboratory of Aquatic Economic Animal Disease Control in Guangdong Higher Education Institution (Zhanjiang, Guangdong). At the beginning of the challenge experiment, $1 \mathrm{~mL}$ syringes were used and $200 \mu \mathrm{L}$ of $1 \times 10^{8} \mathrm{~V}$. parahaemolyticus live suspension was injected into the shrimp intramuscularly. The mortality rate was counted every 24 hours postinjection. Subsequently, the cumulative mortality of shrimp after injection to the stabilization period was added up to 7 days.

2.3. Sample Collection. Before sampling, shrimp were fasted for $24 \mathrm{~h}$, then counted and weighed in repetition units. Five shrimps were randomly selected in each tank, blotted with filter paper, and stored at $-20^{\circ} \mathrm{C}$ for routine nutrient analysis of the whole body. In each tank, another 8 shrimps were ran- domly selected, whose blood was drawn from the pericardial cavity with sterile syringes. The blood was rested at $4^{\circ} \mathrm{C}$ for 12 hours and centrifuged at $4000 \mathrm{rpm}$ for $10 \mathrm{~min}$ (Thermo Fisher, USA). The supernatant was aspirated, and then, the serum was stored at $-80^{\circ} \mathrm{C}$ for later serum index testing. Another 10 shrimps in each replicate were randomly selected and sacrificed, whose intestine tissue was separated on aseptic workbench, washed with $0.65 \%$ normal saline, and immediately stored at $-80^{\circ} \mathrm{C}$ for further test of enzyme activity, gene expression, intestinal microbiota, and transcriptome analysis.

Three additional shrimps were selected from each replicate, whose intestines were taken and preserved in $4 \%$ formaldehyde solution. The intestinal Alcian blue-periodic acid Schiff sections were made by Sevier Biotechnology Co., Ltd. (Guangzhou, China); the muscle and fold were later observed using a light microscope (Leica, DM6000), then measured using cellSens Standard 1.8 software, and photographed using LAS 3.8 software. Ten viewing fields of each slice were randomly selected for measurement.

2.4. Growth Parameters and Biochemical Analysis. Growth parameters were calculated according to the following formulas:

$$
\begin{gathered}
\text { Weight gain }(\mathrm{WG}, \%)=\frac{100 \times(\text { final weight }- \text { initial weight })}{\text { initial weight }}, \\
\text { Specific growth rate }\left(\mathrm{SGR}, \% \cdot \text { day }^{-1}\right)=\frac{100 \times(\ln \text { finalweight }-\ln \text { initialweight })}{\text { days of feeding experiment }}, \\
\text { Feed conversion ratio }(\mathrm{FCR})=\frac{\text { feed consumed }}{\text { weight gain }}, \\
\text { Survival rate }(\mathrm{SR}, \%)=100 \times\left(\frac{\text { final shrimp number }}{\text { initial shrimp number }}\right) .
\end{gathered}
$$

The approximate-analysis detection of moisture, crude protein, and crude lipid was performed following the standard procedures of the Association of Official Analytical Chemists [27].

\subsection{Determination of Biochemical Parameters and Enzyme} Activity. After absorbing the surface water with filter paper, the intestinal tissues were accurately weighed. According to the ratio of weight $(\mathrm{g})$ : volume $(\mathrm{mL})=1: 9$, normal saline was added to mix with gut tissues. The intestinal tissues were water-bathed at $0^{\circ} \mathrm{C}$, shred, and then homogenized and later centrifuged at $2500-3000 \mathrm{rpm}$ for $10 \mathrm{~min}$ (Thermo Fisher, USA). Finally, the supernatant was taken and stored at $-80^{\circ} \mathrm{C}$ for enzyme activity assay.

The serum biochemical parameters were determined by commercial kits obtained from Jiancheng Biological Engineering Institute (96T, Nanjing, China), including Malondialdehyde (MDA), superoxide dismutase (SOD), catalase (CAT), glutathione peroxidase (GSH-Px), and phenol oxidase (PO), which adopted the methods described by Ray et al. [28]. In addition, the following indexes in serum was detected using the methods described by Ayiku et al. [29], including lysozyme (LZM), glutamic pyruvic transaminase (GPT), glutamic oxalacetic transaminase (GOT), alkaline 
TABLE 1: Ingredient compositions and nutrient contents of test diets $(\mathrm{g} / \mathrm{kg})$.

\begin{tabular}{|c|c|c|c|c|c|c|}
\hline \multirow{2}{*}{ Ingredients } & \multicolumn{6}{|c|}{ Diets } \\
\hline & FM & SAP0 & SAP1 & SAP2 & SAP3 & SAP4 \\
\hline Fish meal & 250 & 175 & 175 & 175 & 175 & $\overline{175}$ \\
\hline Cottonseed protein concentrate & 0.0 & 84.6 & 84.6 & 84.6 & 84.6 & 84.6 \\
\hline Shrimp shell powder & 60.0 & 60.0 & 60.0 & 60.0 & 60.0 & 60.0 \\
\hline Soybean meal & 100.0 & 100.0 & 100.0 & 100.0 & 100.0 & 100.0 \\
\hline Corn protein flour & 100.0 & 100.0 & 100.0 & 100.0 & 100.0 & 100.0 \\
\hline Peanut meal & 100.0 & 100.0 & 100.0 & 100.0 & 100.0 & 100.0 \\
\hline Wheat flour & 250.0 & 250.0 & 250.0 & 250.0 & 250.0 & 250.0 \\
\hline Fish oil & 15.0 & 20.1 & 20.1 & 20.1 & 20.1 & 20.1 \\
\hline Soy lecithin & 25.0 & 25.0 & 25.0 & 25.0 & 25.0 & 25.0 \\
\hline Vitamin and mineral premix ${ }^{\mathrm{a}}$ & 10.0 & 10.0 & 10.0 & 10.0 & 10.0 & 10.0 \\
\hline Choline chloride & 5.0 & 5.0 & 5.0 & 5.0 & 5.0 & 5.0 \\
\hline Vitamin C & 1.0 & 1.0 & 1.0 & 1.0 & 1.0 & 1.0 \\
\hline Calcium dihydrogen phosphate & 20.0 & 20.0 & 20.0 & 20.0 & 20.0 & 20.0 \\
\hline Attractant & 1.0 & 1.0 & 1.0 & 1.0 & 1.0 & 1.0 \\
\hline Antioxidant & 0.5 & 0.5 & 0.5 & 0.5 & 0.5 & 0.5 \\
\hline Microcrystalline cellulose & 62.5 & 45.4 & 35.4 & 25.4 & 15.4 & 5.4 \\
\hline Methionine $^{\mathrm{b}}$ & 0.00 & 0.7 & 0.7 & 0.7 & 0.7 & 0.7 \\
\hline Lysine $^{\mathrm{b}}$ & 0.00 & 1.7 & 1.7 & 1.7 & 1.7 & 1.7 \\
\hline $\mathrm{SAP}^{\mathrm{c}}$ & 0.00 & 0.00 & 10.0 & 20.0 & 30.0 & 40.0 \\
\hline \multicolumn{7}{|l|}{ Nutrient contents (air dry matter) } \\
\hline Moisture $^{\mathrm{d}}$ & 116.5 & 112.5 & 118.8 & 115.1 & 102.3 & 118.0 \\
\hline Crude protein ${ }^{\mathrm{d}}$ & 391.1 & 393.5 & 397.9 & 394.3 & 402.5 & 393.7 \\
\hline Crude lipid $^{\mathrm{d}}$ & 73.3 & 81.6 & 79.4 & 70.7 & 75.4 & 79.4 \\
\hline $\operatorname{Ash}^{\mathrm{d}}$ & 107.9 & 101.4 & 100.0 & 105.3 & 112.2 & 106.4 \\
\hline
\end{tabular}

${ }^{a}$ Vitamin and mineral premix ( $\mathrm{kg}^{-1}$ of diet) includes the following contents: thiamine, $5 \mathrm{mg}$; riboflavin, $10 \mathrm{mg}$; vitamin A, $5000 \mathrm{IU}$; vitamin E, $40 \mathrm{mg}$; vitamin D3, $1000 \mathrm{IU}$; menadione, $10 \mathrm{mg}$; pyridoxine, $10 \mathrm{mg}$; biotin, $0.1 \mathrm{mg}$; cyanocobalamin, $0.02 \mathrm{mg}$; calcium pantothenate, $20 \mathrm{mg}$; folic acid, $1 \mathrm{mg}$; niacin, $40 \mathrm{mg}$; vitamin C, $150 \mathrm{mg}$; iron, $100 \mathrm{mg}$; iodine, $0.8 \mathrm{mg}$; cupper, $3 \mathrm{mg}$; zinc, $50 \mathrm{mg}$; manganese, $12 \mathrm{mg}$; selenium, $0.3 \mathrm{mg}$; and cobalt, $0.2 \mathrm{mg}$. ${ }^{\mathrm{b}}$ Adding methionine and lysine was to avoid amino acid imbalance after fishmeal replacement. 'SAP refers to the sulfate-based alginate polysaccharide supplementation, which was provided by Haixingyuan Biological Technology Co., Ltd. (Qingdao, China). ${ }^{\mathrm{d}}$ Moisture, crude protein, crude lipid, and ash were measured values.

TABLE 2: Essential amino acid (EAA) profiles (\%) of the test diets used in the experiment.

\begin{tabular}{lcccccc}
\hline \multirow{2}{*}{ Amino acids } & \multicolumn{7}{c}{ Test diets } \\
& FM & SAP0 & SAP1 & SAP2 & SAP3 & SAP4 \\
\hline Threonine & 1.33 & 1.28 & 1.29 & 1.32 & 1.34 & 1.33 \\
Valine & 1.77 & 1.75 & 1.74 & 1.62 & 1.63 & 1.61 \\
Methionine & 0.68 & 0.63 & 0.65 & 0.67 & 0.66 & 0.71 \\
Isoleucine & 1.39 & 1.35 & 1.35 & 1.46 & 1.49 & 1.42 \\
Leucine & 3.13 & 3.05 & 3.06 & 3.20 & 3.27 & 3.21 \\
Tyrosine & 1.13 & 1.08 & 1.14 & 1.45 & 1.47 & 1.57 \\
Phenylalanine & 1.75 & 1.82 & 1.82 & 2.03 & 2.10 & 2.17 \\
Lysine & 1.95 & 2.01 & 1.91 & 2.04 & 2.06 & 2.05 \\
Histidine & 0.92 & 0.95 & 0.94 & 1.01 & 1.04 & 1.06 \\
Arginine & 2.24 & 2.53 & 2.57 & 2.55 & 2.62 & 2.59 \\
\hline
\end{tabular}

phosphatase (AKP), and acid phosphatase (ACP). Besides, the activity of intestinal trypsin, lipase, and amylase was detected using the 96T Elisa kits obtained from Meilian Bio- technology Co., Ltd. (Shanghai, China). Totally, the experimental operations were carried out strictly according to the kit instructions. Each sample was tested in triplicate.

2.6. Intestinal Microbiome Analysis. The intestinal microbiota (16S V3 + V4 amplified region) of L. vannamei was detected using microbiome $16 \mathrm{~S}$ rDNA sequencing technology, with the assistance of Gene Denovo Biotechnology Co., Ltd. (Guangzhou, China). Samples for microbiome analysis were three replicates per treatment. The soil DNA kit (Magen Co., Ltd., China) was used to extract microbiota DNA. PCR (polymerase chain reaction) was used to amplify the $16 \mathrm{~S}$ rDNA V3 + V4 region of the chromosomal DNA. In addition, the PCR was conducted according to the experimental steps: $95^{\circ} \mathrm{C}$ for $2 \mathrm{~min}$, after that 27 cycles at $98^{\circ} \mathrm{C}$ for $10 \mathrm{~s}$, then $62^{\circ} \mathrm{C}$ for $30 \mathrm{~s}$ and $68^{\circ} \mathrm{C}$ for $30 \mathrm{~s}$, and finally $68^{\circ} \mathrm{C}$ for $10 \mathrm{~min}$. Besides, the adopted primer sequences were $5^{\prime}$-CCTACGGGNGGCWGCAG-3' (341F) and $5^{\prime}$-GGAC TACHVGGGTATCTAAT-3' (806R), respectively. Amplification products were performed separation using $2 \%$ agarose gels and then operated purification using the DNA Gel Extraction Kit obtained from Axygen Biosciences 
(Silicon Valley, USA). Moreover, the amplification products were quantified performing the ABI SteponePlus real-time fluorescence quantitative PCR system (Life Technologies, USA). Subsequently, the purified amplification products were pooled equimolarly and performed pair-end sequencing $(2 \times 250)$ on the Illumina Hiseq2500 platform (San Diego, USA) following the standard protocol. Ultimately, all raw data generated by the present microbiome were deposited in the sequence read archive (SRA) of the National Center for Biotechnology Information (NCBI) under the registration number PRJNA741699.

After performing the noisy sequence filtration and chimerism checking, the clustering was performed using $97 \%$ similarity as the threshold (VSEARCH, version 10.00) [30]. Based on the above, the clustered data was divided into identical operational taxonomic units (OTUs)[31]. The number of OTUs was plotted against the total number of sequences drawing sparse curves, to evaluate the sequencing depth. Besides, the intergroup Venn analysis was performed using the microbial indication analysis function of the Omicsmart platform (https://www.omicshare.com/tools/), to identify unique and shared OTUs. The alpha indexes were calculated operating the Mothur software (version v.1.30, http://www .mothur.org/). In addition, the overall bacterial composition was compared using principal coordinate analysis (PCoA) function on the Omicsmart platform (https://www .omicshare.com/tools/). Microbial species annotation was performed using RDP Classifier (version 2.2, http:// sourceforge.net/projects/rdpclassifier/), referring to the SILVA database (https://www. arbsilva.de/).

\subsection{Intestinal Transcriptome Analysis}

2.7.1. RNA Extraction, cDNA Library Construction, and Illumina Sequencing. Total RNA from Pacific white shrimp intestine tissue was extracted using TRIzol Kit obtained from Invitrogen (California, USA), strictly following the instructions. Then, the total RNA was treated with RNase-free DNase I obtained from Tiangen Biochemical Technology Co., Ltd. (Beijing, China). The quality of RNA was tested by using Agilent 2100 Bioanalyzer (Agilent Technologies). Besides, the RNA quantity was measured by a spectrophotometer (NanoDrop Technologies). The RNA integrity was evaluated by using $1.5 \%$ agarose-gel electrophoresis, and later examined by absorption spectroscopy. After that, $5 \mu \mathrm{g}$ highquality RNA of each group were pooled and sequenced on a HiSeq2000 platform (Illumina, USA), with the operating assistance of Gene Denovo Biotechnology Co., Ltd. (Guangzhou, China). In order to deeply comprehend the profile of gene expression, the entire transcriptome de novo assembly was sequenced using a 100 bp paired-end Solexa strategy, including the first- and second-strand cDNA synthesis. The sequencing data generated in this transcriptome study has been uploaded in the Genome Sequence Archive of the National Genomics Data Center (https://ngdc.cncb.ac.cn/). Besides, the assigned accession of the submission is CRA004649.

2.7.2. De Novo Assembly and Unigene Annotation. To prepare for assembly, raw reads produced by Illumina Hiseq
2000 sequencing platform from seven digital libraries were cleaned by using a software tool in SeqPrep (https://github .com/jstjohn/SeqPrep) and Sickle (https:/github.com/ najoshi/sickle), according to filter adaptor reads, including the reads $(>10 \% \quad Q)$ which were below 20 bases (quality $<20$ ) and low-quality reads with unclear bases. After that, de novo assembly was performed using short read assembling program, Trinity, whose version was numbertrinityrnaseq-r2014-04-13, as described by Zhao et al. [32]. The transcript clustering into unigenes was conducted by virtue of TIGR gene indices clustering tools in accordance with sequence similarity and length, which adopted the method of Geo et al. [33]. The assembled unigenes were conducted for gene similarity by virtue of BLASTx tool (http:// www.ncbi.nlm.nih.gov/BLAST/) with an $E$-value approach of $1 e-5$ to the following databases in National Coalition Building Institute, including nonredundant protein database (http://www.ncbi.nlm.nih.gov), Swiss-Prot protein database (http://www.expasy.ch/sprot), COG/KOG database (http:// www.ncbi.nlm.nih.gov/COG), Kyoto Encyclopedia of Genes and Genomes database (http://www.genome.jp/kegg), and GO used Blast2GO, as described by Stefan et al. [34]. And then, protein functional annotations may be received based on the best alignments.

2.7.3. Analysis of Differentially Expressed Genes. As described by Langmead and Salzberg [35], the expression levels of genes were evaluated by reflecting clean reads to unigenes using Bowtie2; after that, they computed for each sample with RSEM using the method described by Dewey and Li [36]. Based on the suggestion conducted by Mortazavi et al. [37], all gene abundance was normalized and calculated using uniquely mapped reads, according to read per kilobase of exon model in per million mapped reads. Based on the method described by Smyth [38], the identification of different gene expressions between treatment groups was conducted by virtue of using $\mathrm{R}$ package. In multiple tests, the significance of gene expression was assessed by the $P$ value of false discovery rate (FDR) below 0.001. Adopting the following judgment principle, if the FDR was below 0.001, besides a higher than twofold change in expression across libraries ( $\log 2$ ratio value above 1$)$ was observed, the gene would be considered as significant difference. When the value of $\log 2$ fold was more than 1 , the transcripts would be considered to upregulate. On the contrary, if the value of $\log 2$ fold was below 1 , the downregulated transcripts were observed. What is more, the coexpression gene of different gene expressions between treatment groups was deeply understood by KEGG pathway enrichment, which was based on the Kyoto Encyclopedia of Genes and Genomes database (https://www.kegg.jp/kegg/).

2.7.4. Validation of Real-Time Quantitative PCR Analysis. To verify the RNA-Seq data of transcriptome in Pacific white shrimp, the extracted RNA which were used before for transcriptome were detected by (quantitative real-time) qRT-PCR analysis. In this context, nine significantly differentially expressed genes related to antioxidant and innate immunity were opted after comprehensive comparison. 
The specific primers used in this study are shown in Table 3, which were synthesized in Shenggong Biological Engineering Co., Ltd. (Shanghai, China).

The RT-qPCR reaction was performed using Applied Biosystems 7500 Real-Time PCR System obtained from Life Technologies (California, USA), whose experimental steps adopt SYBR @ Premix Ex Taq ${ }^{\mathrm{TM}}$ kit (Takara, Kusatsu). All experimental operations were carried out in strict accordance with the instructions. The thermal cycling conditions were conducted following $95^{\circ} \mathrm{C}$ for $2 \mathrm{~min}$, after that 40 cycles of $95^{\circ} \mathrm{C}$ for $10 \mathrm{~s}$, and then $72^{\circ} \mathrm{C}$ for $20 \mathrm{~s}$. Besides, all reactions were operated in triplicate. According to the test method described by Vieira-Girão et al. [39], $\beta$-actin was set as the reference gene in shrimp. The gene expression was calculated using the $2^{-\Delta \Delta \mathrm{CT}}$ method, described by $\mathrm{Du}$ et al. [40].

2.8. Statistical Analysis. The statistical analysis was conducted using SPSS software 19.0 (IBM, USA). All data are expressed as mean \pm standard error of the mean (SEM). The data normality and variance homogeneity were tested adopting Shapiro-Wilk and Levene's test, respectively. Two following analysis methods were conducted in the present study: (1) the FM group and SAP0 group were subjected to T-test; (2) one-way analysis of variance (ANOVA) was conducted to analyze SAP groups (including SAP0, SAP1, SAP2, SAP3, and SAP4 groups), and then, multiple comparison between groups was tested using the Tukey method. Besides, $P<0.05$ was considered as the statistical significance.

2.9. Ethics Statement. The experimental procedure has been approved by the animal care and ethics committee of Guangdong Ocean University (GDOU).

\section{Results}

3.1. Growth Performance. As shown in Table 4, there were no significant differences among groups in initial weight (IW) and SR. The final weight (FW) and FCR of the FM group were significantly different from those of the SAP0 group $(P<0.05)$. The maximum and minimum of $\mathrm{FW}$ appeared in the SAP2 group and SAP4 group, respectively $(P<0.05)$. The WG and SGR in SAP2 and SAP3 groups were significantly higher than those in other groups $(P<0.05)$. Besides, the SAP4 group was the minimum of WG and SGR $(P<0.05)$. On the contrary, the FCR in the SAP4 group was the maximum between groups, while FCR in SAP1, SAP2, and SAP3 groups was significantly lower than that in other groups $(P<0.05)$. Based on the polynomial curve analysis of SGR among SAP groups, Figure 2 suggests that the optimal level of SAP supplementation for shrimp was $1.91 \%$.

3.2. Whole-Body Proximate Composition. As shown in Table 5, the dry matter of shrimps in the FM group was significantly different from that in the SAP0 group $(P<0.05)$, but there was no significant difference among the SAP treatments $(P>0.05)$. The crude protein of the FM group was significantly higher than that of the SAP0 group; and crude protein of SAP0 and SAP1 groups was significantly lower than that of the other groups $(P<0.05)$; besides, the crude protein of SAP2, SAP3, and SAP4 groups had no difference between groups $(P>0.05)$. The crude lipid of the FM group was significantly higher than that of the SAP0 group $(P<0.05)$; the crude lipid content of the SAP group showed a trend of firstly decreasing and then increasing as follows: the SAP0 and SAP4 groups were significantly higher than the other groups, while the SAP2 and SAP3 groups were the least significant values $(P<0.05)$. The ash content of the FM group was significantly lower than that of the SAP0 group $(P<0.05)$; yet, there was no significant difference in ash content among SAP groups $(P>0.05)$.

3.3. Serum Biochemical Parameters. Table 6 shows the serum biochemical parameters in shrimp. Among the 10 parameters that have been investigated, the values in the FM group were significantly different from those in the SAP0 group $(P<0.05)$. The MDA content of SAP0 and SAP1 groups was significantly higher than that of the SAP2, SAP3, and SAP4 group $(P<0.05)$. SOD activity showed an upward trend among SAP groups; besides, the SAP0 group was significantly lower than the other groups $(P<0.05)$. The CAT activity of SAP0 and SAP1 groups was significantly lower than that of SAP2, SAP3, and SAP4 groups $(P<0.05)$. The GSH-Px activity in the SAP0 group was the minimum, while that in the SAP4 group was the maximum value $(P<0.05)$. There was no significant difference in GSH-Px activity among SAP1, SAP2, and SAP3 groups $(P>0.05)$. The PO activity of SAP3 and SAP4 was significantly higher than that of SAP0 and SAP2 $(P<0.05)$, while SAP0, SAP1, and SAP2 had no significant difference in PO activity $(P>0.05)$. The LZM activity showed an upward trend among SAP groups, and the AP0 group was the minimum; besides, the SAP4 group has the maximum value $(P<0.05)$. The activity change of GPT and GOT had similar downward trend as follows: the SAP0 group has the significant maximum values, while the minimum was the SAP3 or SAP4 group $(P<0.05$ ). There was no significant difference in AKP activity among SAP groups $(P>0.05)$. The ACP activity in SAP2 and SAP3 groups was significantly higher than that in other groups, yet the minimum was in the SAP0 group $(P<0.05)$.

3.4. Intestine Digestive Enzymes. Table 7 shows the change in digestive enzyme activities of shrimp intestine. The activities of trypsin, lipase, and amylase in the FM group were significantly higher than those in the SAP0 group $(P<0.05)$. The trypsin activity was significantly lowest in the SAP0 group $(P<0.05)$, while there was no significant difference among SAP1, SAP2, SAP3, and SAP4 groups $(P>0.05)$. The lipase activity of the SAP2 group was the significant maximum, while the minimum value appeared in the SAP0 group $(P<0.05)$. The maximum of amylase activity appeared in the SAP3 group, while the SAP0 and SAP1 groups were significantly lower than in other groups $(P<0.05)$.

3.5. Intestinal Morphology. Figure 3 shows the intestinal histology of Litopenaeus vannamei. After feeding with SAP supplementation for 8 weeks, the shrimps showed relatively favorable intestinal morphology. As shown in Figure 3(b), the intestinal histology indexes of the FM group were 
TABLE 3: Sequence of primers used in this study.

\begin{tabular}{|c|c|c|c|}
\hline Genes & GenBank no. & Forward $\left(5^{\prime}-3^{\prime}\right)$ & Reverse $\left(5^{\prime}-3^{\prime}\right)$ \\
\hline Toll-1 & DQ923424 & GACCATCCCTTTTACACCAGACT & CCTCGCACATCCAGGACTTTTA \\
\hline Akirin & KC415269 & TCACCGTCTCCATCACCTGC & CAAGCCAATACCTTGTCATACTCC \\
\hline TRAF6 & HM581680 & TGGGTCCGTGTCCAGTGAT & ACAAACAACCACACACAAGCAG \\
\hline ALF & DQ208705 & CGCTTCACCGTCAAACCTTAC & GCCACCGCTTAGCATCTTGTT \\
\hline Crustin & AF430076 & CACGAGGCAACCATGAAGG & TCTTGCACCAATACCTGCAGT \\
\hline LZM & AY170126 & TGTTCCGATCTGATGTCC & GCTGTTGTAAGCCACCC \\
\hline Hsp70 & AY645906 & ATGGCAAAGGCACCTGCTGT & TGAGCACCATCGAGGAGATCT \\
\hline SOD & HM371157 & AGCCAATGACGTAAGCG & ACCATCACAAGAAACCC \\
\hline CAT & AY518322 & AGAGGGTTGTGCATGCTAAG & CAGCTGATCCACTCTCACСТ \\
\hline$\beta$-Actin & AF300705 & CCACGAGACCACCTACAACATC & TTAGAAGCACTTCCTGTGAACAATG \\
\hline
\end{tabular}

$\beta$-Actin was set as the reference gene. Abbreviation: TRAF6: TNF receptor associated factor 6; ALF: antilipopolysaccharide factor; LZM: lysozyme; Hsp70: heat shock protein 70; SOD: superoxide dismutase; CAT: catalase.

TABLE 4: Effect of sulfate-based alginate polysaccharide supplementation on growth performance in L. vannamei.

\begin{tabular}{lcccccc}
\hline Parameters & FM & SAP0 & SAP1 & SAP2 & SAP3 & SAP4 \\
\hline IW (g) & $0.74 \pm 0.02$ & $0.73 \pm 0.01$ & $0.75 \pm 0.03$ & $0.74 \pm 0.01$ & $0.73 \pm 0.01$ & $0.73 \pm 0.01$ \\
FW (g) & $7.48 \pm 0.14^{*}$ & $7.07 \pm 0.12^{\mathrm{ab}}$ & $7.48 \pm 0.31^{\mathrm{bc}}$ & $7.72 \pm 0.35^{\mathrm{c}}$ & $7.56 \pm 0.03^{\mathrm{bc}}$ & $6.80 \pm 0.43^{\mathrm{a}}$ \\
WG (\%) & $916.36 \pm 21.39$ & $872.61 \pm 8.98^{\mathrm{ab}}$ & $898.89 \pm 45.18^{\mathrm{ab}}$ & $942.97 \pm 33.95^{\mathrm{b}}$ & $941.79 \pm 14.09^{\mathrm{b}}$ & $834.29 \pm 39.49^{\mathrm{a}}$ \\
SGR $\left(\% \cdot\right.$ day $\left.^{-1}\right)$ & $4.37 \pm 0.07$ & $4.29 \pm 0.02^{\mathrm{ab}}$ & $4.34 \pm 0.15^{\mathrm{ab}}$ & $4.42 \pm 0.12^{\mathrm{b}}$ & $4.42 \pm 0.03^{\mathrm{b}}$ & $4.21 \pm 0.14^{\mathrm{a}}$ \\
FCR & $1.02 \pm 0.03^{*}$ & $1.12 \pm 0.09^{\mathrm{b}}$ & $1.03 \pm 0.05^{\mathrm{a}}$ & $1.01 \pm 0.06^{\mathrm{a}}$ & $1.01 \pm 0.01^{\mathrm{a}}$ & $1.14 \pm 0.08^{\mathrm{b}}$ \\
SR (\%) & $98.33 \pm 0.83$ & $97.50 \pm 2.50$ & $100.00 \pm 0.00$ & $100.00 \pm 0.00$ & $100.00 \pm 0.00$ & $100.00 \pm 0.00$ \\
\hline
\end{tabular}

Values are means $\pm \operatorname{SEM}(n=3)$. Values in the same column with different superscript letters mean significantly different among SAP groups (ANOVA, $P$ $<0.05)$. The superscript $*$ of the FM group indicates that the FM group is significantly different from the SAP0 group $(T$ test, $P<0.05)$. Abbreviations: IW: initial weight; FW: final weight.

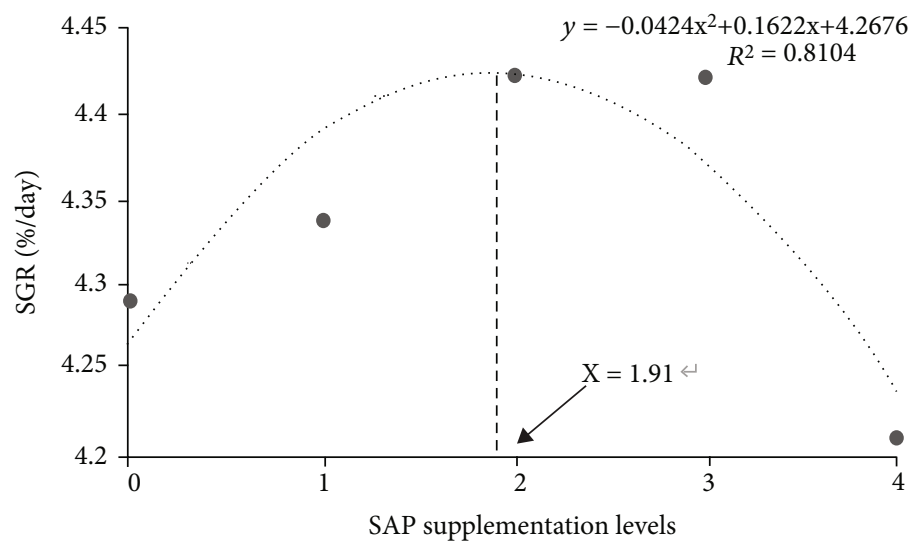

FIgUre 2: Polynomial curve model analysis of SGR in Pacific white shrimp fed with SAP diets for 8 weeks.

significantly different from those of the SAP0 group, including muscle thickness, fold height, and fold width $(P<0.05)$. The muscle thickness among SAP treatments showed a trend of increasing firstly and then decreasing; the SAP2 group was the maximum, while the SAP0 group was the minimum significantly $(P<0.05)$. The villus height of SAP2 and SAP3 was significantly higher than that of SAP0, SAP3, and SAP4 groups $(P<0.05)$; yet, there was no difference in villus height between SAP0, SAP3, and SAP4 groups
$(P>0.05)$. The villus width of SAP2 and SAP3 groups was significantly higher than that of the SAP0 group $(P<0.05)$, while there was no significance in villus width among SAP0, SAP1, and SAP4 groups $(P>0.05)$.

\subsection{Intestinal Microbiota Analysis}

3.6.1. Richness and Diversity Analysis. Figure 4 shows the alpha-index analysis of shrimp microbiota. The core OTU 
TABLE 5: Effect of sulfate-based alginate polysaccharide supplementation on whole-body proximate composition ( $\mathrm{g} / \mathrm{kg}$, dry weight) in $L$. vannamei.

\begin{tabular}{lcccccc}
\hline Parameters & FM & SAP0 & SAP1 & SAP2 & SAP3 & SAP4 \\
\hline Dry matter & $272.0 \pm 5.8^{*}$ & $259.0 \pm 4.9$ & $257.1 \pm 4.2$ & $254.2 \pm 4.7$ & $251.3 \pm 10.4$ & $248.6 \pm 5.7$ \\
Crude protein & $764.1 \pm 9.2^{*}$ & $752.3 \pm 3.5^{\mathrm{a}}$ & $754.9 \pm 2.8^{\mathrm{a}}$ & $764.6 \pm 1.7^{\mathrm{b}}$ & $767.8 \pm 3.3^{\mathrm{b}}$ & $763.5 \pm 6.7^{\mathrm{b}}$ \\
Crude lipid & $78.7 \pm 1.3^{*}$ & $64.1 \pm 6.2^{\mathrm{c}}$ & $55.2 \pm 2.9^{\mathrm{b}}$ & $42.5 \pm 3.4^{\mathrm{a}}$ & $46.8 \pm 6.2^{\mathrm{a}}$ & $64.3 \pm 5.8^{\mathrm{c}}$ \\
Ash & $124.7 \pm 1.9^{*}$ & $140.7 \pm 1.4$ & $138.2 \pm 0.8$ & $139.5 \pm 1.7$ & $138.9 \pm 2.5$ & $140.9 \pm 4.7$ \\
\hline
\end{tabular}

Values are means \pm SEM $(n=3)$. Values in the same column with different superscript letters mean significantly different among SAP groups (ANOVA, $P$ $<0.05)$. The superscript $*$ of the FM group indicates that the FM group is significantly different from the SAP0 group $(T$ test, $P<0.05)$.

TABLE 6: Effect of sulfate-based alginate polysaccharide supplementation on serum biochemical parameters in L. vannamei.

\begin{tabular}{|c|c|c|c|c|c|c|}
\hline Parameters & FM & SAP0 & SAP1 & SAP2 & SAP3 & SAP4 \\
\hline $\mathrm{MDA}(\mathrm{nmol} / \mathrm{mL})$ & $8.44 \pm 0.34^{*}$ & $11.38 \pm 1.94^{\mathrm{b}}$ & $11.18 \pm 0.87^{\mathrm{b}}$ & $9.24 \pm 0.38^{\mathrm{a}}$ & $8.91 \pm 0.33^{\mathrm{a}}$ & $8.94 \pm 0.19^{a}$ \\
\hline $\mathrm{SOD}(\mathrm{U} / \mathrm{mL})$ & $97.19 \pm 8.59^{*}$ & $86.77 \pm 3.69^{\mathrm{a}}$ & $108.74 \pm 12.58^{\mathrm{b}}$ & $140.18 \pm 3.33^{\mathrm{d}}$ & $118.56 \pm 6.57^{\mathrm{c}}$ & $135.03 \pm 5.99^{\mathrm{d}}$ \\
\hline CAT (U/mL) & $5.48 \pm 0.27^{*}$ & $2.05 \pm 0.15^{\mathrm{a}}$ & $2.56 \pm 0.14^{\mathrm{a}}$ & $4.73 \pm 0.19^{\mathrm{b}}$ & $4.22 \pm 0.12^{\mathrm{b}}$ & $4.86 \pm 0.25^{\mathrm{b}}$ \\
\hline GSH-Px (U/L) & $90.86 \pm 1.49^{*}$ & $49.73 \pm 2.09^{\mathrm{a}}$ & $86.41 \pm 9.71^{b}$ & $90.82 \pm 8.52^{\mathrm{bc}}$ & $87.61 \pm 13.94^{\mathrm{b}}$ & $102.94 \pm 7.61^{\mathrm{c}}$ \\
\hline $\mathrm{PO}(\mathrm{U} / \mathrm{L})$ & $38.73 \pm 4.03^{*}$ & $32.61 \pm 1.78^{\mathrm{a}}$ & $37.84 \pm 1.51^{\mathrm{ab}}$ & $34.19 \pm 4.84^{\mathrm{a}}$ & $38.34 \pm 1.32^{\mathrm{b}}$ & $38.20 \pm 2.31^{b}$ \\
\hline LZM (U/L) & $2.45 \pm 0.16^{*}$ & $1.52 \pm 0.09^{\mathrm{a}}$ & $3.63 \pm 0.23^{b c}$ & $3.07 \pm 0.12^{\mathrm{ab}}$ & $3.74 \pm 0.46^{\mathrm{bc}}$ & $4.73 \pm 0.65^{\mathrm{c}}$ \\
\hline GPT (U/L) & $50.54 \pm 4.14^{*}$ & $62.72 \pm 5.49^{c}$ & $52.46 \pm 5.90^{\mathrm{b}}$ & $47.14 \pm 8.64^{\mathrm{a}}$ & $53.92 \pm 3.79^{\mathrm{b}}$ & $45.57 \pm 3.81^{\mathrm{a}}$ \\
\hline GOT (U/L) & $38.57 \pm 2.49^{*}$ & $44.75 \pm 4.04^{\mathrm{c}}$ & $39.53 \pm 6.17^{b}$ & $38.20 \pm 6.39^{\mathrm{ab}}$ & $35.34 \pm 2.44^{\mathrm{a}}$ & $41.61 \pm 4.98^{\mathrm{b}}$ \\
\hline $\mathrm{AKP}(\mathrm{U} / \mathrm{mL})$ & $6.70 \pm 0.36^{*}$ & $4.33 \pm 0.84$ & $5.32 \pm 1.91$ & $5.02 \pm 0.92$ & $5.01 \pm 1.22$ & $4.56 \pm 0.28$ \\
\hline $\mathrm{ACP}(\mathrm{U} / \mathrm{mL})$ & $9.26 \pm 1.94^{*}$ & $6.17 \pm 0.38^{\mathrm{a}}$ & $9.7 \pm 1.05^{\mathrm{b}}$ & $13.01 \pm 1.14^{\mathrm{c}}$ & $12.91 \pm 1.47^{\mathrm{c}}$ & $8.67 \pm 0.89^{b}$ \\
\hline
\end{tabular}

Values are means $\pm \operatorname{SEM}(n=3)$. Values in the same column with different superscript letters mean significantly different among SAP groups (ANOVA, $P$ $<0.05)$. The superscript $*$ of the FM group indicates that the FM group is significantly different from the SAP0 group $(T$ test, $P<0.05)$.

TABLE 7: Effect of sulfate-based alginate polysaccharide supplementation on intestine digestive enzymes in L. vannamei.

\begin{tabular}{|c|c|c|c|c|c|c|}
\hline Parameters & FM & SAP0 & SAP1 & SAP2 & SAP3 & SAP4 \\
\hline Trypsin (U/L) & $0.92 \pm 0.04^{*}$ & $0.63 \pm 0.02^{\mathrm{a}}$ & $1.21 \pm 0.07^{\mathrm{b}}$ & $1.14 \pm 0.05^{\mathrm{b}}$ & $1.26 \pm 0.05^{\mathrm{b}}$ & $1.26 \pm 0.06^{\mathrm{b}}$ \\
\hline Lipase $(\mathrm{U} / \mathrm{mL})$ & $617.14 \pm 27.26^{*}$ & $541.22 \pm 22.63^{\mathrm{a}}$ & $551.48 \pm 18.76^{\mathrm{a}}$ & $619.45 \pm 14.14^{\mathrm{b}}$ & $579.63 \pm 10.96^{\mathrm{ab}}$ & $568.60 \pm 18.80^{\mathrm{ab}}$ \\
\hline Amylase (U/mg) & $1.17 \pm 0.15^{*}$ & $0.76 \pm 0.09^{\mathrm{a}}$ & $0.98 \pm 0.10^{\mathrm{a}}$ & $1.09 \pm 0.07^{\mathrm{ab}}$ & $2.27 \pm 0.11^{\mathrm{c}}$ & $1.34 \pm 0.07^{\mathrm{b}}$ \\
\hline
\end{tabular}

Values are means $\pm \operatorname{SEM}(n=3)$. Values in the same column with different superscript letters mean significantly different among SAP groups (ANOVA, $P$ $<0.05)$. The superscript $*$ of the FM group indicates that the FM group is significantly different from the SAP0 group $(T$ test, $P<0.05)$.

(operational taxonomic unit) accounted for 181. Clearly, the proportions of shared OTUs within each group were $84.19 \%, 79.39 \%, 90.05 \%, 88.73 \%, 71.83 \%$, and $74.49 \%$, respectively. This shows that there was a stable core of dominant bacteria in intestinal microbiota. Besides, the microbiota coverage of each group was all close to $99 \%$, which suggests that the sequencing depth of this intestinal microbiota analysis was sufficient. Thus, the experimental results were representative. The ACE and Chaol indexes of the FM group were significantly higher than those of the SAP0 group $(P<0.05)$. Moreover, the ACE and Chaol indexes had similar trend as follows: SAP0 and SAP2 were significantly lower than SAP1, SAP3, and SAP4 $(P<0.05)$. This suggests that the microbiota richness of SAP0 and SAP2 groups was lower than that of the other groups. On the other hand, the Shannon and Simpson indexes of the FM group were not significantly different from those of the SAP0 group $(P>0.05)$. In addition, Shannon and Simpson indexes decreased firstly and then increased with the increasing SAP supplementation levels. Besides, the lowest value appeared in the SAP2 group $(P<0.05)$. The two indexes have inverse proportion relationship with the microbiota diversity. Thus, the microbiota diversity in shrimp gut firstly increased and then decreased as the SAP supplementation increased. And the highest diversity of microbiota occurred in the SAP2 group.

3.6.2. Microbial Community Analysis. Figure 5 reveals the comparison of the overall bacterial composition between treatments. On the one hand, the SAP-containing groups were close to each other (in blue frame), indicating that the bacterial composition was closer inside the SAPcontaining groups. Moreover, the layout of the FM and SAP0 groups was clearly separated from the SAP- 

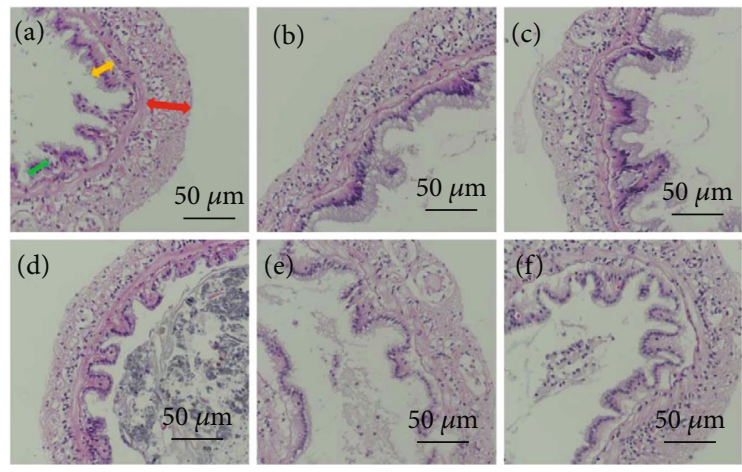

(a)
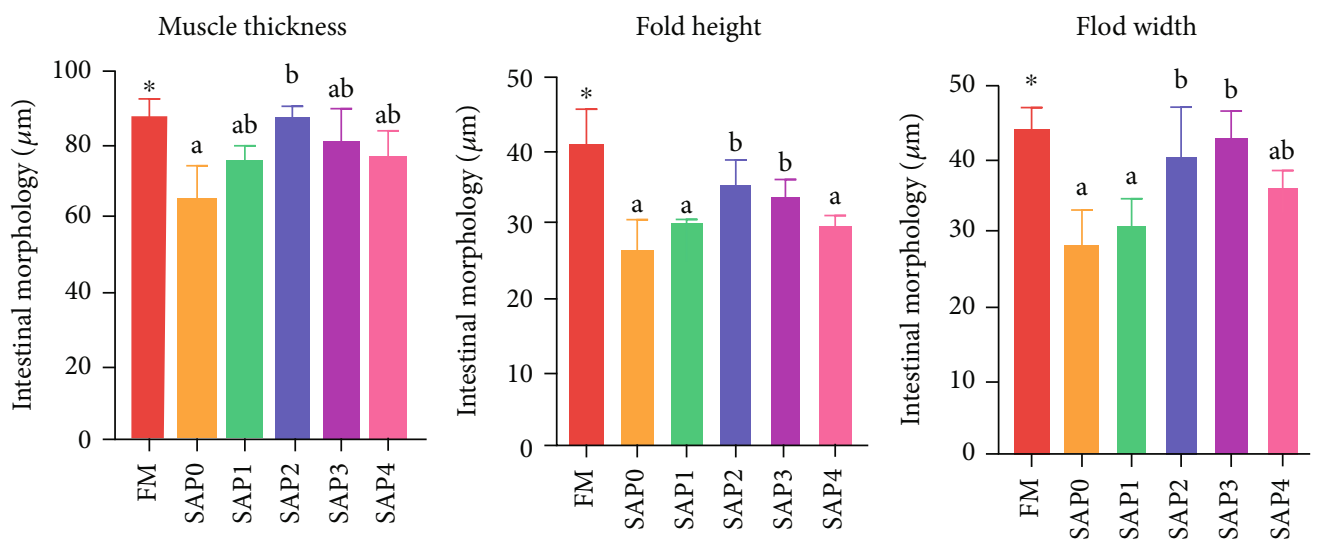

(b)

FIGURE 3: (a) Intestinal histology of L. vannamei fed with sulfate-based alginate polysaccharide supplementation for 8 weeks. Shrimp intestine transverse photomicrograph segments were presented as follows: red arrow, muscle thickness; yellow arrow, fold height; and green arrow, fold width. The coding (A-F) refers to groups FM, SAP0, SAP1, SAP2, SAP3, and SAP4, respectively. (b) Effect of intestinal histology measurement $(\mu \mathrm{m})$ in $L$. vannamei. Ten viewing fields of each slice were randomly selected for measurement. Notes: values are means $\pm \operatorname{SEM}(n=3)$. Values in the same row with different superscript letters mean significantly different among SAP groups (ANOVA, $P<0.05)$. The superscript $*$ of the FM group indicates that the FM group is significantly different from the SAP0 group ( $T$ test, $P<0.05$ ).

containing groups, reflecting shrimp fed with or without supplementing SAP that caused structural difference on the bacterial composition of shrimp intestinal microbiota.

At the phylum level of intestinal microbiota (Figure 6(a)), the relative abundance of Verrucomicrobia in the FM group was significantly higher than that in the SAP0 group $(P<0.05)$. Yet, the relative abundance of Tenericutes and Cyanobacteria in the FM group was significantly lower than that in the SAP0 group $(P<0.05)$. As the SAP supplements increased, the relative abundances of Bacteroidetes and Verrucomicrobia showed an upward trend; the minimum values of their abundance appeared in the SAP0 group, while the maximums appeared in SAP2 or SAP3 groups $(P<0.05)$. The relative abundances of Proteobacteria and Tenericutes showed a downward trend; the maximum occurred in the SAP0 group, while the SAP4 or SAP3 group was the significant minimum $(P<0.05)$. There was no significant difference in the relative abundance of Actinobacteria and Planctomycetes among groups $(P>0.05)$. The abundance of Firmicutes in the SAP1 group was significantly lower than that of other groups $(P<0.05)$. The abundance of Cyanobacteria in the SAP0 group was significantly higher than that of other groups, while the abundance in SAP1 and SAP2 groups was significantly lower than that in SAP3 and SAP4 groups $(P<0.05)$.

As shown in Figure 6(b), the relative abundance of Vibrio, Hoppeia, Haloferula, Motilimonas, and Actibacter in the FM group was significantly higher than that in the SAP0 group $(P<0.05)$. Moreover, the relative abundance of Halocynthiibacter, Pseudoalteromonas, and Candidatus Bacilloplasma in the FM group was significantly lower than that in the FM group $(P<0.05)$. The relative abundance of Vibrio and Candidatus Bacilloplasma showed a downward trend between SAP groups; besides, the SAP0 and SAP4 groups were the maximum and minimum, respectively $(P<0.05)$. The abundance of Hoppeia and Haloferula in SAP0 and SAP2 groups was significantly lower than that in other groups $(P<0.05)$. The relative abundances of Haloferula, Motilimonas, and Tamlana increased firstly and then decreased with the increased SAP supplement levels; besides, the maximum and minimum were SAP3 and SAP0 groups, respectively $(P<0.05)$. The relative abundance of Halocynthiibacter in the SAP0 group was significantly higher than that in other groups, while the abundance of Halocynthiibacter in the SAP1 group was the minimum value $(P<0.05)$. The abundance of Pseudoalteromonas in the SAP0 group was significantly higher than that in other 


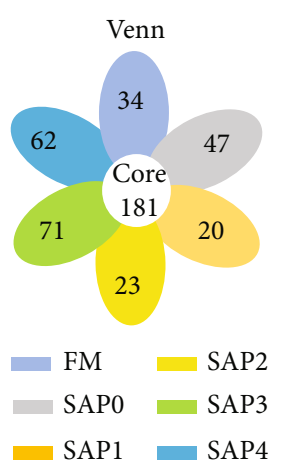

(a)

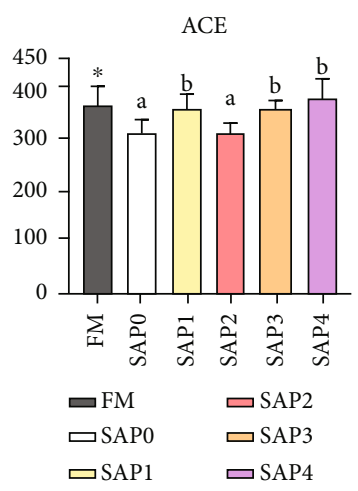

(c)

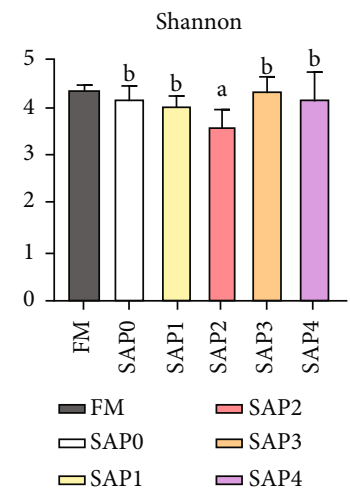

(e)

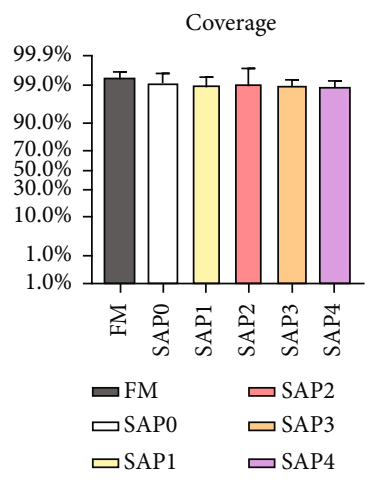

(b)

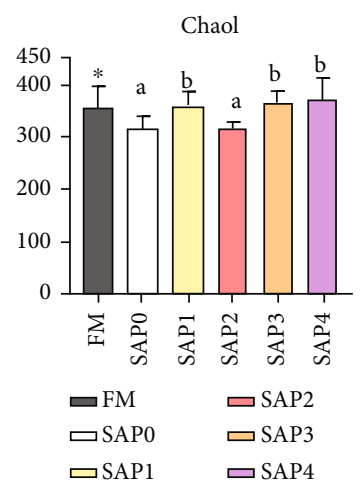

(d)

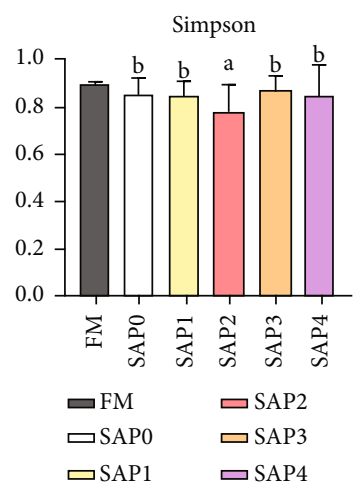

(f)

FIGURE 4: Alpha diversity indices of intestinal microbiota in L. vannamei fed with sulfate-based alginate polysaccharide supplementation for 8 weeks ((a) shared OTU Venn analysis; (b) coverage analysis; (c, d) richness analysis; (e, f) diversity analysis). Notes: values are means \pm SEM $(n=3)$. Values in the same row with different superscript letters mean significantly different among SAP groups $($ ANOVA, $P<$ 0.05). The superscript $*$ of the FM group indicates that the FM group is significantly different from the SAP0 group ( $T$ test, $P<0.05$ ).

groups, while the abundance in SAP1 and SAP2 groups was lower than that in SAP3 and SAP4 groups $(P<0.05)$. The abundance of Tenacibaculum firstly decreased and then increased; besides, the relative abundance of SAP1, SAP2, and SAP3 groups was significantly lower than that of SAP0 and SAP4 groups $(P<0.05)$. The relative abundance of Actibacter in the SAP1 group was significantly higher than that in other SAP treatments $(P<0.05)$.

\subsection{Intestinal Transcriptome Analysis}

3.7.1. Illumina Sequencing and De Novo Assembly. This experiment was aimed at testing the intestinal transcriptome of Pacific white shrimp using Illumina $\mathrm{HiSeq}^{\mathrm{TM}}$ 2000, which is compared with a reference transcriptome detection method. As shown in Table 8, the raw data (bp) produced by each treatment group was above 6 billion. Among them, the proportion of clean reads Q20 was over 97\%. Moreover, the proportion of clean reads Q30 was above 92\%. After splicing and redundancy removal, all clean reading strips were further assembled, and the range of N50 fluctuated from $47892 \mathrm{bp}$ to $60239 \mathrm{bp}$. Besides, the GC percentage was greater than $43 \%$. In brief, the results show off the good quality control of the transcriptome data.

3.7.2. Function Annotation, Pathway Assignment, and Differentially Expressed Gene Analysis. In order to express 


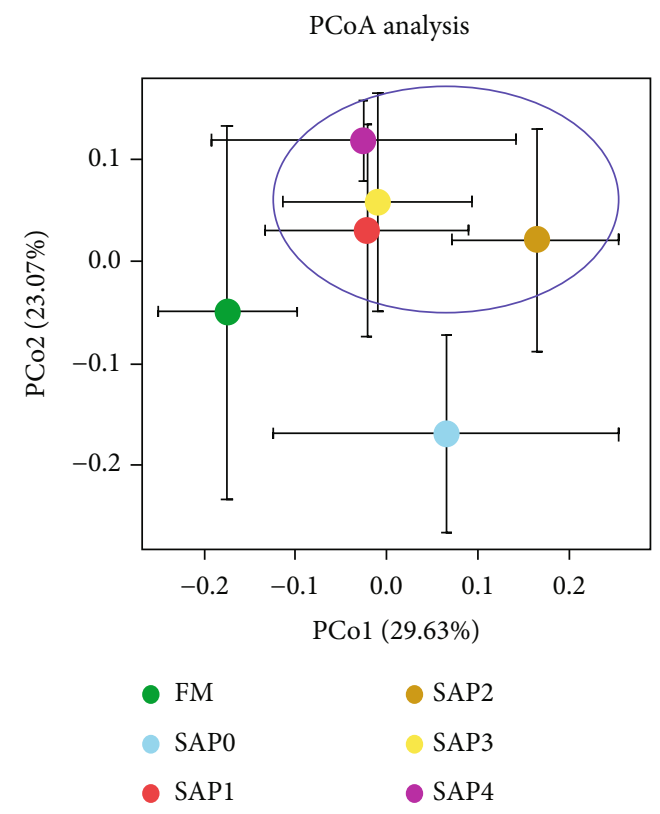

Figure 5: Comparison of overall bacterial composition between treatments in shrimp intestinal microbiota. The cross line of the value is the error bar within the group.

the characteristics of gene products, the GO (gene ontology) enrichment analysis has been divided into three major classification categories (Figure 7A), including biological process, molecular function, and cellular component. Regarding the biological process, each subcategory displayed the downward trend, among which the subcategories with higher values were cellular process, single-organism process, metabolic process, biological regulation, and regulation of biological process. In terms of molecular function, the two more prominent categories were binding and catalytic activity. Moreover, the prominent subcategories with higher values were cell, cell part, organelle, membrane, and organelle part in the cellular component category.

In addition, the KEGG (Kyoto Encyclopedia of Genes and Genomes) pathway enrichment analysis (Figure 7(b)) was mainly divided into six aspects, namely, metabolism, human diseases, organismal systems, genetic information processing, cellular processes, and environmental information processing. Regarding the metabolism, global and overview maps occupied the highest and most prominent data. Moreover, the infectious diseases and cancers had relatively high values in the classification of human diseases. Additionally, the endocrine system, immune system, digestive system, and nervous system occupied the main front row position in organic systems. On the other hand, the four subdirectories accounted for relatively close proportions in genetic information processing, namely, translation; folding, sorting, and degradation; transcription; and replication and repair. In cellular processes, they were located in numerical order as follows: transport and catabolism, cell growth and death, cellular community eukaryotes, and cell motility. Finally, the signal transduction was the most important approach in the environmental information processing.
The representative comparisons (FM-vs-SAP0 and SAP0-vs-SAP2) were selected for analysis, performing the differentially expressed gene analysis in Figure 8. The results showed that there were more upregulated unigenes in the comparison of FM-vs-SAP0; besides, the extra amount was 334. What is more, the downregulation of unigenes is 406 more than the upregulation of unigenes in the comparison of SAP0-vs-SAP2. Taken together, the Venn diagram analysis found that there were 980 unigenes with similar expression patterns, the proportion of which was $41.58 \%$. At the same time, the heat map analysis suggested that the differential gene expression between FM/SAP0 and SAP2/SAP3 was highly related (green frames in Figure 8(d)). These results recommended that the differential gene expression patterns of $L$. vannamei fed different diets had a certain degree of similarity, which implemented the conservative strategy.

3.7.3. Validation of Transcriptome by Quantitative RealTime PCR. In order to identify and verify the transcriptome expression profile, three treatments (including the FM, SAP0, and SAP2) had been selected, to compare the expression of significantly differential genes involved in nonspecific immunity and antioxidant capacity after comprehensive comparison.

Reflecting from a macro point of view, the comparison between RNA-Seq and qRT-PCR showed the degree of similarity, which indicates that the transcriptome data had a certain degree of accuracy and reliability (Figure 9). Specifically, the expression of signal molecules (Toll-1 and Akirin) and antibacterial genes (ALF, Crustin, and LZM) in the SAP2 group was significantly upregulated $(P<0.05)$, comparing with the SAP0 group. Moreover, the expression levels of genes related to antioxidation (HSP70 and CAT) were significantly upregulated in the FM and SAP2 groups $(P<0.05)$.

3.8. Challenge Test. The cumulative mortality of challenge test is demonstrated in Figure 10. The cumulative mortality in the FM group was significantly lower than that in the SAP0 group $(P<0.05)$. The cumulative mortality displayed a trend that decreased firstly and then increased among SAP groups: the SAP0 group was significantly higher than the other SAP groups, while the SAP3 group was the least significant in terms of cumulative mortality $(P<0.05)$. There was no significant difference between SAP1, SAP2, and SAP4 groups $(P>0.05)$.

\section{Discussion}

The Pacific white shrimp is a fast-growing marine organism. During its growing larval stage, amino acids play important roles in the protein synthesis. Therefore, amino acid nutritional intake is a key prerequisite for meeting growth requirements (Hiroki \& [41]). In addition, relevant studies found that dietary plant proteins generally contain antinutritional factors and unbalanced amino acid composition, which would cause inhibitory response on the growth of aquatic animals, such as hybrid grouper (Epinephelus fuscoguttatus $\$ \times E$. lanceolatus $\left.{ }^{*}\right)$ [16] and golden pompano 


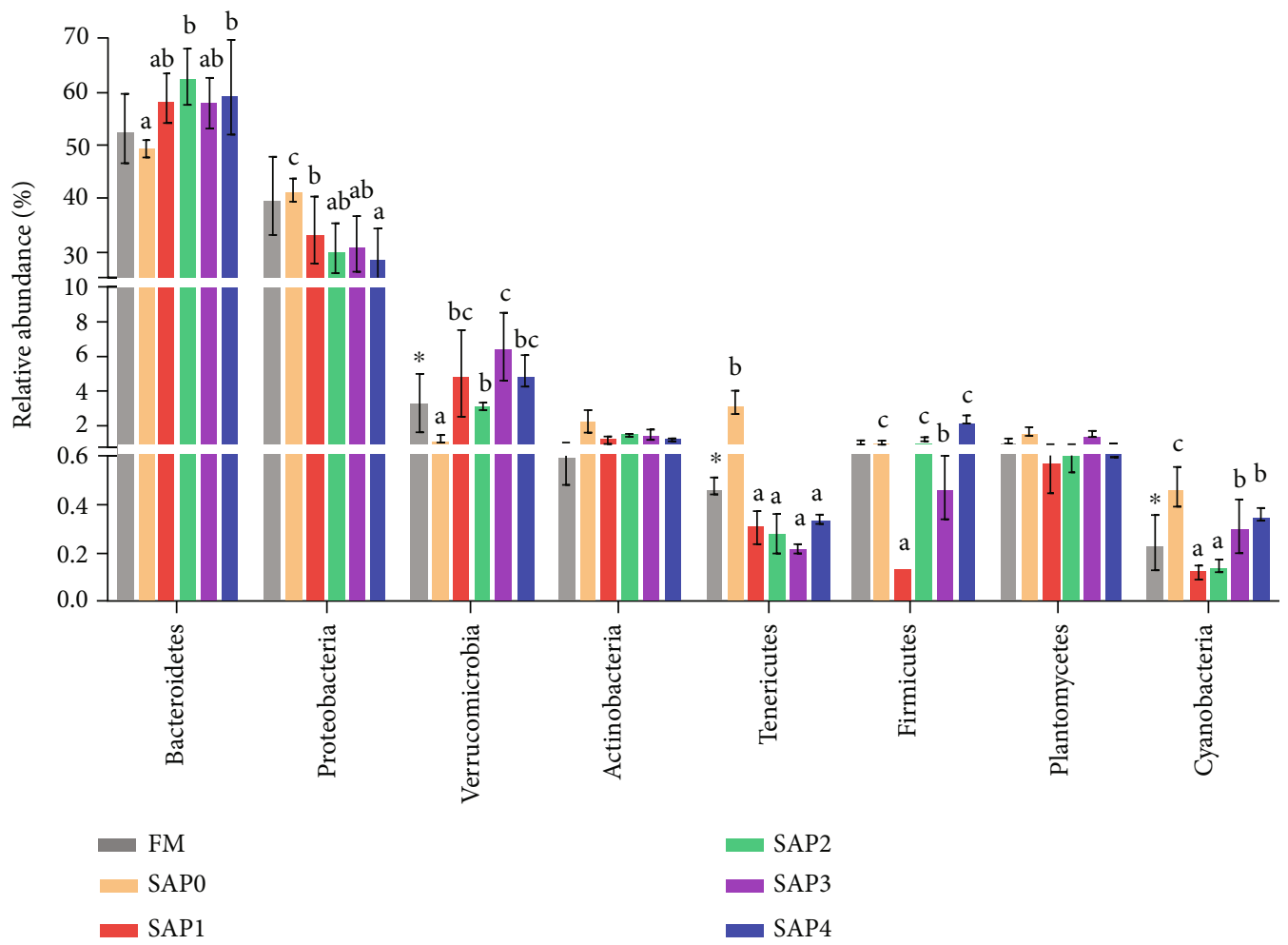

(a)

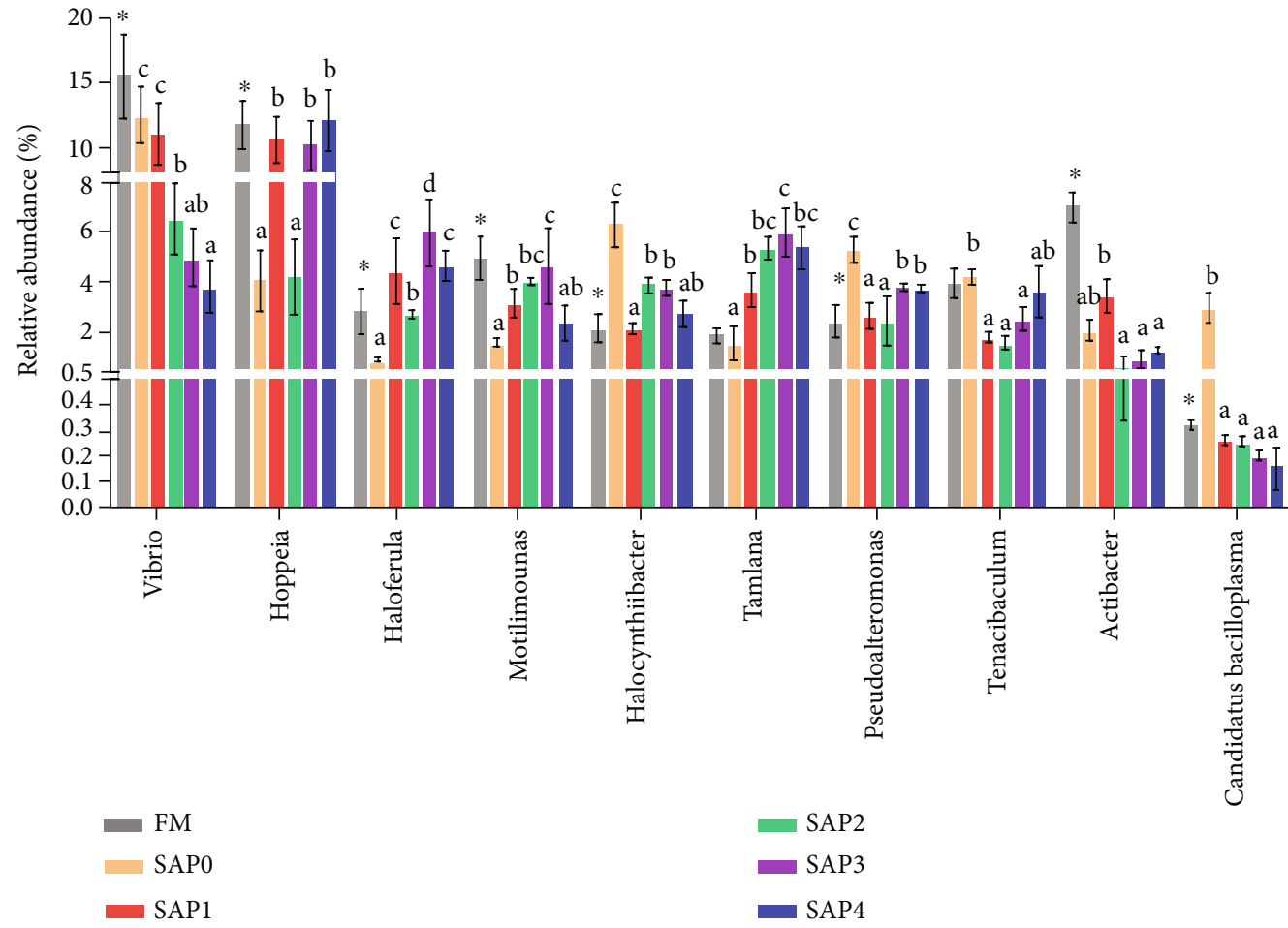

(b)

FIGURE 6: (a) Relative abundance of major bacterial phyla in L. vannamei fed with sulfate-based alginate polysaccharide supplementation for 8 weeks. (b) Relative abundance of major bacterial genera in L. vannamei fed with sulfate-based alginate polysaccharide supplementation for 8 weeks. Notes: values are means \pm SEM $(n=3)$. Values in the same row with different superscript letters mean significantly different among SAP groups (ANOVA, $P<0.05$ ). The superscript $*$ of the FM group indicates that the FM group is significantly different from the SAP0 group ( $T$ test, $P<0.05$ ). 
TABLE 8: Summary of RNA-Seq data for L. vannamei fed with sulfate-based alginate polysaccharide supplementation for 8 weeks.

\begin{tabular}{|c|c|c|c|c|c|c|}
\hline Type & FM & SAP0 & SAP1 & SAP2 & SAP3 & SAP4 \\
\hline Raw data (bp) & 7085797200 & 6524317800 & 6008991600 & 6921824400 & 6076856400 & 6493628400 \\
\hline Clean reads Q20 (\%) & $97.69 \%$ & $97.58 \%$ & $97.31 \%$ & $97.62 \%$ & $97.63 \%$ & $97.69 \%$ \\
\hline Clean reads Q30 (\%) & $93.54 \%$ & $93.49 \%$ & $92.97 \%$ & $93.31 \%$ & $93.63 \%$ & $93.55 \%$ \\
\hline N50 (bp) & 60239 & 52522 & 47892 & 59855 & 49157 & 54839 \\
\hline GC percentage (\%) & $43.55 \%$ & $44.06 \%$ & $44.72 \%$ & $43.58 \%$ & $43.92 \%$ & $43.75 \%$ \\
\hline
\end{tabular}

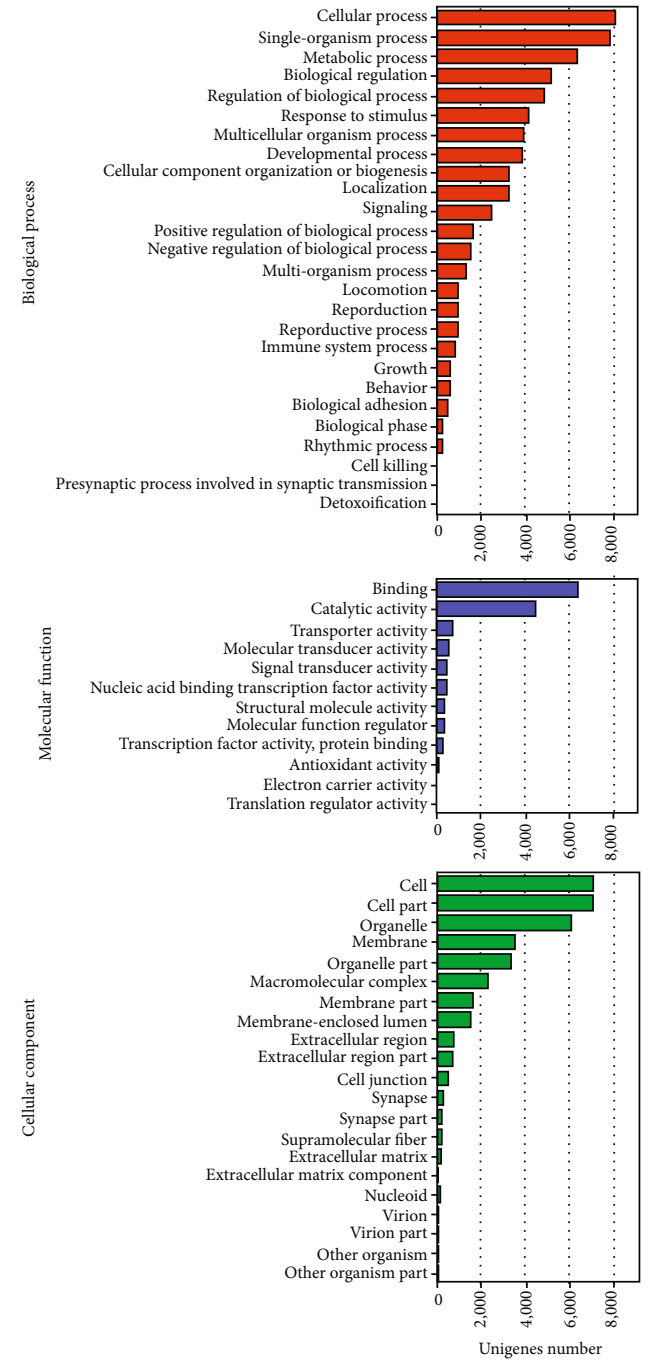

(a)

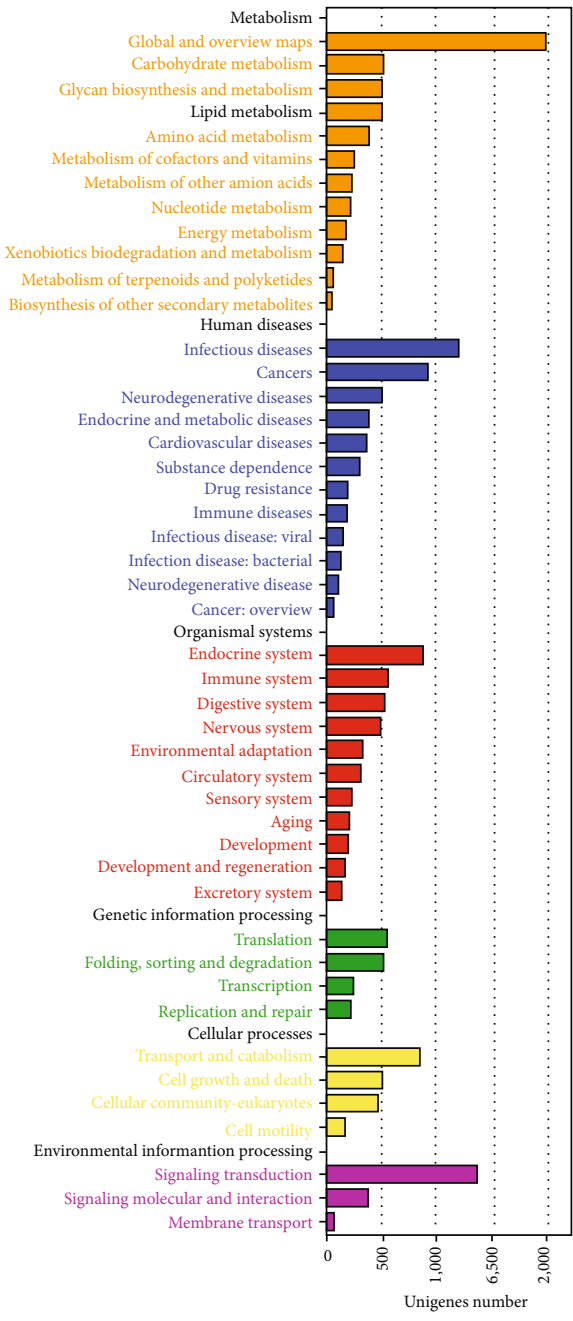

(b)

Figure 7: (a) Gene ontology enrichment analysis of assembled unigenes in L. vannamei RNA-Seq. Notes: the horizontal axis indicates GO functional categories; the vertical axis (superscript numbers) indicates number of unigenes in each category. (b) KEGG pathway enrichment analysis in L. vannamei RNA-Seq. Notes: the vertical axis indicates KEGG pathway categories; the horizontal axis indicates number of unigenes in each pathway.

(Trachinotus ovatus) [18]. In the present experiment, the SAP0 treatment was simultaneously lacking supplementation in the context of replacing fishmeal. Correspondingly, shrimp in the SAP0 group displayed worse growth performance. On the other hand, the WG and SGR of shrimp were improved with the increase of SAP supplementation. This suggests that the growth performance of shrimp benefited from SAP supplementation. This may be caused by the fact that fermented seaweed is rich in various mineral elements, organic acids, polysaccharides, and natural antibiotics. These rich active substances help to enhance protein synthesis in shrimp and thus promote growth $[42,43]$. This is also verified by the higher crude protein content in the whole-body component of SAP2, SAP3, and SAP4. This result is similar 


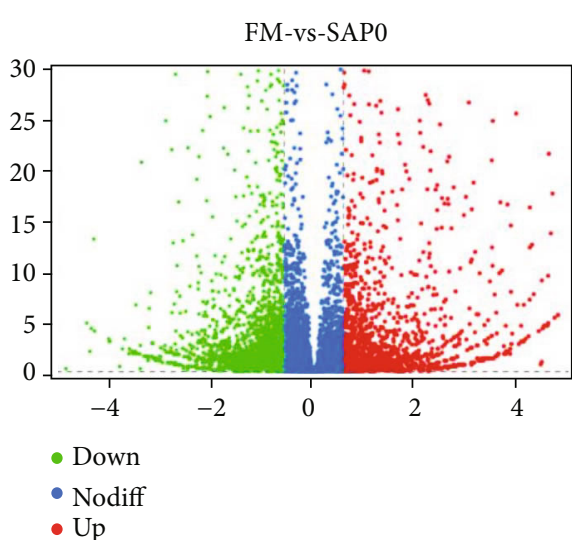

(a)

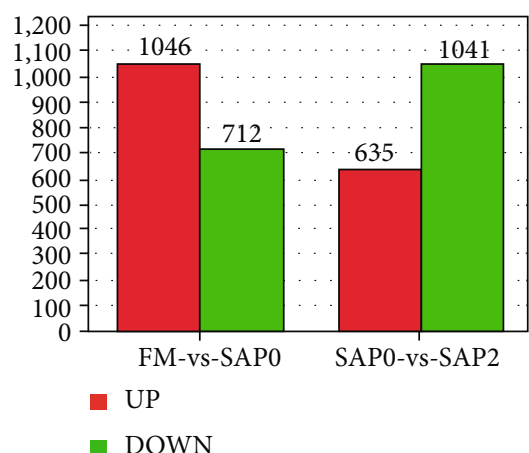

(c)

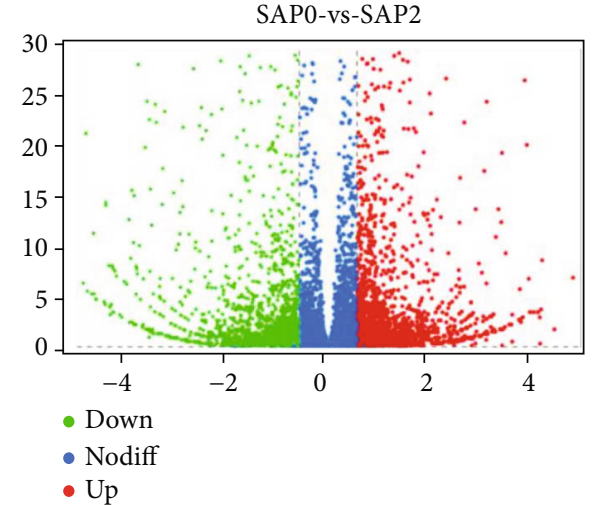

(b)
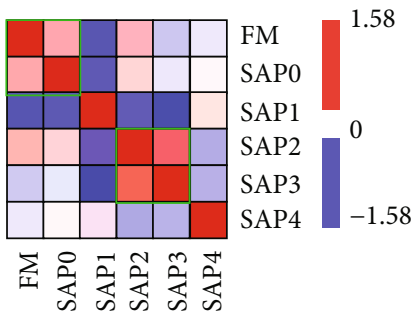

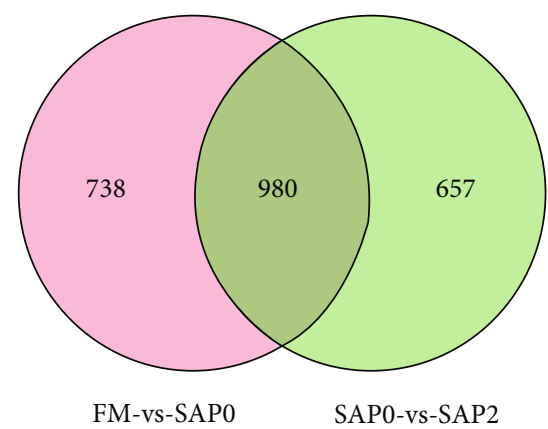

(e)

Figure 8: (a, b) Volcano map of differentially expressed genes. (c). Numerically pairwise comparison of differentially expressed genes in FMvs-SAP0 and SAP0-vs-SAP2. (d). Heatmap analysis of correlation between groups. (e). Venn diagram of differentially expressed genes in FM-vs-SAP0 and SAP0-vs-SAP2.

to the conclusion reported by Islam et al. [44], who found that supplementary fermented seaweed could improve organism growth and protein synthesis. On the other hand, the results of this experiment also found that only moderate SAP supplements were beneficial. Excessive seaweed polysaccharide may cause excessive fermentation of intestinal microorganisms and imbalance of intestinal microenvironment. At the same time, the relatively excessive polysaccharide would reduce the viscosity and hygroscopicity of the feed and lower the palatability of the feed [45]. The factors mentioned above are not conducive to the growth of shrimps. This may explain why the growth-promoting effect is not excellent in high-concentration SAP treatments.
Compared to marine bony fishes, the Pacific white shrimp is a relatively simple species in terms of body structure. The shrimp has an open blood system where blood flows throughout the body. Therefore, serum is an important dynamic response indicator of shrimp body functions [28]. In this experiment, we focus on the antioxidant and nonspecific immunity indicators of shrimp serum. In one respect, antioxidant capacity is an important means to remove metabolic waste and maintain internal environment balance [16, 46]. The SAP0 group contained the highest MDA content. Moreover, the enzyme activities related to SOD, CAT, GSH-Px, and PO increased in FM and SAP treatments. Specifically, SOD is an antioxidant metalloenzyme that catalyzes the dismutation of superoxide anion radicals, which plays a 

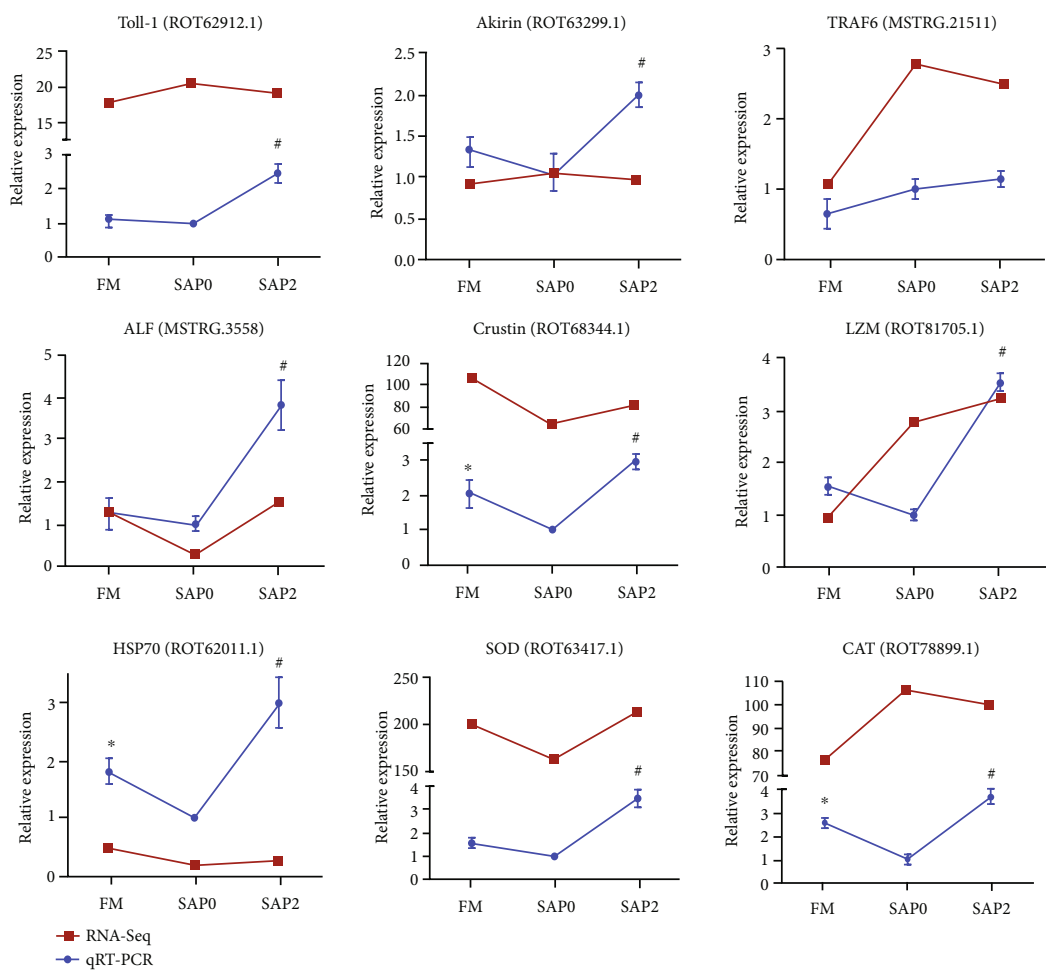

FIGURE 9: Comparison of the expression of RNA-Seq and qRT-PCR verification. To validate the RNA-Seq data, the relative mRNA levels of 9 significantly differently expressed genes in the gut of shrimp were examined by qRT-PCR. Notes: the expression levels of the RNA-Seq analysis were calculated based on the RPKM values. Regarding the qRT-PCR, values are means \pm SEM $(n=3)$. Besides, the superscript $*$ or ${ }^{\#}$ indicates that the FM or SAP2 group is significantly different from the SAP0 group, respectively $(P<0.05)$.

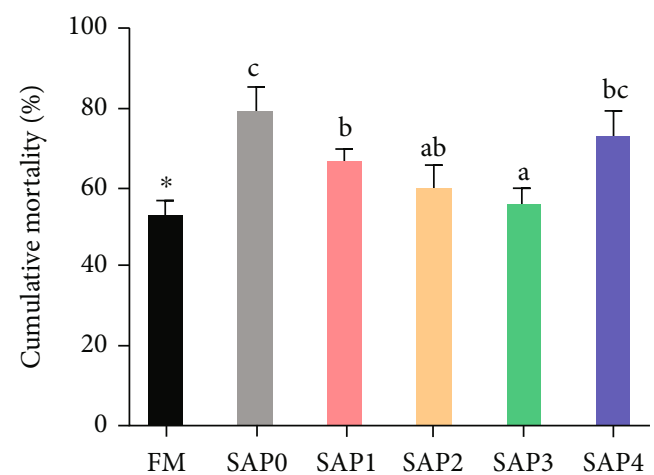

Figure 10: Cumulative mortality of shrimp challenged with Vibrio parahaemolyticus. The mortality rate was counted every 24 hours postinjection. Values are means $\pm \operatorname{SEM}(n=3)$. Values in the same row with different superscript letters mean significantly different among SAP groups (ANOVA, $P<0.05$ ). The superscript * of the FM group indicates that the FM group is significantly different from the SAP0 group ( $T$ test, $P<0.05$ ).

vital role in the oxidative and antioxidant balance of the organism [47]. In addition, CAT is a marker enzyme of peroxisome, and its enzymatic activity provides the antioxidant defense mechanism for the organism [48]. What is more, GSH-Px is an important peroxide-decomposing enzyme widely present in the body, which reduces toxic peroxides to nontoxic hydroxyl compounds and promotes the decomposition of $\mathrm{H}_{2} \mathrm{O}_{2}$, thus protecting the structure and function of cell membranes from interference and damage by peroxides [15]. Besides, the PO plays an important role in the process of resisting pathogenic microbial infestation, which mainly includes some resistance-related antioxidant enzyme reactions in the phenolic metabolic system [49]. The elevated serum antioxidant capacity of the shrimp organism may be related to dietary SAP supplement. According to relevant study, seaweed extracts are rich in phenolic compounds, the pigments of which are similar to carotenoids [50]. Besides the active substances have the effect of scavenging free radicals and enhancing the antioxidant capacity [51]. Furthermore, the special feature of SAP is closely related to its structural complexity. The molecular structure of SAP is branched, and then, some branching structures can be sulfated. SAP has highly variable functions and structures, which depend on the repetition of oligosaccharide motifs in the polysaccharide, the nature of the oligosaccharide chains, the degree of branching, the molecular weight, and the degree of sulfation [52]. Totally, these highly variable molecular structures confer antioxidant activity to SAP.

As the invertebrates, nonspecific immunity of Pacific white shrimp plays an important role in its maintenance of organism resistance and health. Lysozyme can effectively hydrolyze the peptidoglycan of bacterial cell wall, which can be used as a natural anti-infective substance with bactericidal effect [53]. Moreover, AKP and ACP are major indicators of growth and immune function in aquatic animals, which play important roles in cell regulation and nutrient transport [28]. Thus, AKP, ACP, and lysozyme are closely 
related in the nonspecific immunity in shrimp organism. The present result showed that SAP0 contained lower activities of LZM, AKP, and ACP, compared to the FM group. Related researches have suggested that dietary fishmeal replacement with plant protein would decrease the nonspecific immunity in aquatic animals, which was verified in hybrid grouper [54] and Pacific white shrimp [55]. From another perspective, the activities of LZM, AKP, and ACP showed an elevated trend in the SAP-treated groups. This suggests that SAP supplementation enhanced the nonspecific immunity activity in shrimp serum. Similarly, the efficacy of seaweed extract analogues in enhancing organismspecific immunity is proved in the results studied on Labeo rohita [56]. On the other hand, the results of this experiment showed that the GPT and GOT activities were significantly highest in the SAP0 group. GPT and GOT play major roles in the hepatopancreas of shrimp. Besides, the GOT and GPT activities in serum are pivotal indexes of the functional stability and organism health [29]. In this study, the GOT and GPT activities increased in the SAP0 group. This indicates to some extent that the fishmeal replacement diet may cause impairment of hepatopancreas function in shrimp. In turn, the activities of GOT and GPT decreased as the levels of SAP supplementation increased. This responded that SAP supplementation improved the hepatopancreas health of shrimp while enhancing nonspecific immunity, again confirming the prebiotic role of seaweed extract analogues [57].

The digestive function relies on the mechanical gastrointestinal motility and chemical action of digestive enzymes. In general, aquatic animals have relatively simple digestive tract and weaker digestive capacity. Besides, the digestive enzymes play crucial roles in food digestion and nutrient absorption through hydrolysis [58]. This experiment revealed that the digestive enzyme activities were significantly lower in the SAP0 group than in the FM group, including the trypsin, lipase, and amylase. Generally, dietary plant protein property would cause decreased activity of digestive enzymes in aquatic animals, which was corroborated by the results in trout (Oncorhynchus mykiss) and sea bream (Sparus aurata) [59]. A related study suggested that the inhibitory effect of plant protein diet on digestive enzyme activity may be related to the presence of antinutritional factors [60]. In the present experiment, the improvement in digestive enzyme activities was obtained with the addition of SAP supplementation. The improved digestive capacity of the shrimp may be related to the role of acidifiers belonging to SAP supplementation. The polysaccharides contained in SAP cannot be digested and absorbed by shrimp but can be broken down by microorganisms in the intestinal tract. Above all, microbial fermentation can hydrolyze polysaccharides and oligosaccharides to produce some beneficial shortchain fatty acids, such as acetic acid and butyric acid. In this context, microbial fermentation causes a decrease of $\mathrm{pH}$ in the intestine, which promotes digestive tract enzymatic activation and nutrient digestion [61].

The intestine is the main organ for the digestion and nutrient absorption in shrimp. A normal histology in the gut maximizes the surface area, which is a good guarantee for the active function of the gut [58]. In the present experiment, we focused on the thickness of muscle layer, villus height, and villus width of the shrimp intestine. Relative to the FM group, the intestinal histology indexes were relatively poor in the SAP0 group. In contrast to the SAP0 group, the SAP2 and SAP3 treatments were again improved, especially in terms of villus height and villus width. Microvilli are numerous tiny protrusions in the intestine that are efficient means of increasing the contact area between the digestive tract and food [28]. The improved intestinal morphology facilitates the shrimp to enhance digestion and absorption, which corresponds to the enhanced digestive capability in this experiment. Similarly, it was found that dietary seaweed polysaccharides also alleviated intestinal mucosal inflammation and improved intestinal histology in mice (Mus musculus) [62]. This is because algae oligosaccharide dose activates the mannose receptor signaling pathway by eliminating genetic interference and ultimately promotes intestinal epithelial cell recovery [63].

Intestinal microbiota is the general term for the microbial society in the organism's gut. In recent years, intestinal microbiota sequencing has received a lot of attention. This is because studies have found that the intestinal microbiota is closely related to the digestion, immunity, metabolism, and health of the host $[64,65]$. At the same time, an ecologically balanced intestinal microflora is a positive guarantee of intestinal function and a window into intestinal health [66]. In this experiment, Venn analysis elaborated that there was a core proportion in gut microbial structure, even though shrimp from different treatments received different diets. The core of the bacterial composition may be related to the indigenous bacteria. A related study has found that the microflora in the intestine consists of mobile and indigenous bacteria. The indigenous bacteria mainly colonize the organism gut when the host larvae are incubated. Besides, the composition of indigenous bacteria is influenced by the local environment and is somewhat stable $[67,68]$. The present results explained the dynamics of the gut microflora in the context of shrimp receiving different diets. In other words, shrimp fed SAP supplementation obtained higher similarity in the social composition of the microflora. Specifically, the intestinal microbiota is the main point of focus for the probiotic effect of polysaccharide prebiotics [23]. Consistent with the above, polysaccharides and oligosaccharides that cannot be digested by the host but can be fermented by beneficial bacteria into short-chain fatty acids thus improve the intestinal microecology. On the one hand, the proliferation of beneficial bacteria would preferentially occupy the colonial ecological niche of the intestine. In addition, the acidic microecological environment caused by fermentation has an inhibitory effect on conditionally pathogenic bacteria, mainly gram-negative bacteria. Finally, prebiotics themselves can effectively reduce the adhesion protein expression of harmful bacteria, which can also reduce the colonization and further multiplication of harmful bacteria [69]. The present results found that the relative abundance of beneficial bacteria (Bacteroidetes) increased at the phylum level, while the relative abundance of conditional pathogens showed the decreasing trend, such as Proteobacteria and 
Cyanobacteria. Moreover, the results mainly revealed decreasing relative abundance of harmful bacteria at the genus level, such as Vibrio, Pseudoalteromonas, and Candidatus Bacilloplasma. A study conducted by Zhang et al. [62] found an increase in beneficial microorganisms (Ceratobacteraceae) and a decrease in harmful bacteria (Desulfovibrio) in fucoidan oligosaccharide-dosed mice (Mus musculus). Besides, a Pacific white shrimp study came to a similar conclusion that different types of seaweed extracts both improved the gut microflora, specifically increasing the relative abundance of beneficial bacteria (Bacteroidetes, Firmicutes, and Nontuberculous) and decreasing the relative abundance of harmful bacteria ( $\gamma$-Proteobacteria and Vibrioceae) [70].

Transcriptome sequencing is the sum of all RNAs that can be transcribed in a given functional state, mainly including mRNAs and noncoding RNAs [71, 72]. The transcriptome is also the most important regulatory modality of organism. In recent years, transcriptomics has been increasingly studied in aquaculture yield, such as Pacific white shrimp [73] and Sparus aurata [74]. In this experiment, transcriptomic sequencing of the shrimp gut was performed, whose experimental data showed good quality control. The transcriptomic analysis revealed that the regulation of shrimp fed different diets was mainly concentrated in the biological process during the gene ontology enrichment analysis. This is because of more unigenes enriched in the biological process, in comparison to other collection. On the other hand, it was found that the pathways affected by SAP were mainly concentrated in the metabolism, diseases, and organismal system collections, based on the results of KEGG pathway enrichment. Notably, signal transduction was found to be enriched to a relatively high number of unigenes, when further subdivided into the next subset. Whether this is suggesting that the regulatory effect of dietary SAP supplementation was based on the signal transduction is an interesting and worthwhile question to explore. A study conducted by Zhao et al. [63] found that marine fucoidan oligosaccharides alleviated intestinal mucosa in mice. The mechanism was exactly based on the role of fucoidan oligosaccharides in signaling to intestinal cells through the mannose receptor signaling pathway. Further, the present experiment investigated significantly differential gene expression and revealed a degree of similarity in the differential gene expression patterns of Pacific white shrimp fed different diets, which performed a conservative metabolic strategy. The reason for this may be that shrimp is relatively simple and stress-prone invertebrates, thus adopting the cautious metabolic strategy which is more conducive to maintain the homeostasis of their internal environment and survival [75].

The results of RNA-Seq and qRT-PCR were compared in this experiment and showed generally consistent trends, indicating a degree of accuracy and reliability of the transcriptome data [76]. Consistent with the above, in order to explore the signaling role of SAP supplementation, this experiment revealed that the gene expression levels of signaling molecules (Toll-1, Akirin, and TRAF6) were upregulated in the SAP2 group, relative to the SAP0 group. The nonspe- cific immune system is an important line of defense. Toll-1 was found to be actively involved in intrinsic immune signaling [77]. In addition, Akirin is highly conserved evolutionarily and actively involved in regulating the transcription of immune-related target genes in the TLR (Toll-like receptors) pathway downstream [78]. Moreover, TRAF6 is an important component of the TLR superfamily, which can activate the promoters of antimicrobial peptide genes during signaling [79]. After that, the present results suggested a relative upregulation in the expression of antimicrobial peptide-related genes, including ALF, Crustin, and LZM. On this basis, this can be deduced that SAP supplementation may be used to upregulate the expression of antimicrobial peptide genes by regulating nonspecific immune signaling and thus achieving enhanced nonspecific immunity [80]. On the other hand, the FM and SAP2 groups showed increased expression of genes related to antioxidant capacity, including HSP70, SOD, and CAT. HSP70 is a conserved protein used to maintain the homeostasis, which involves in antistress and synergistic immune effects [81]. In other words, dietary fishmeal substitution would decrease the antioxidant capacity of aquatic animals [11]. However, the upregulation of antioxidant-related gene levels in the SAP2 group was found, which was also corroborated by elevated antioxidant enzyme activities in serum. Specifically, SAP supplementation could improve the antioxidant capacity by increasing the antioxidant-related gene expression and enzyme activity in shrimp. This is similar to the suggestion reported on grass carp (Ctenopharyngodon idellus) [57].

The data collected from the challenging experiment postfeeding trial was also a solid argument for the above inference. In this experiment, the cumulative mortality rate of Vibrio parahaemolyticus challenging in the SAP group was all significantly lower than that in the SAP0 group. This indicates that the disease resistance of SAP treatments was significantly improved by the SAP supplementation. In other words, the increased disease resistance of treatments receiving SAP dietary doses may be associated with the upregulated antimicrobial peptide gene expression and the increased antioxidant capacity [21,82]. Similarly, related experiments on Pacific white shrimp found that macroalgae extractions improved the immune response and gut health under the WSSV (white spot syndrome virus) challenge condition [70].

\section{Conclusion}

In summary, the results of this experiment demonstrate that SAP supplementation improved growth, serum antioxidant and nonspecific immunity, intestinal health, and disease resistance in Pacific white shrimp fed fishmeal replacement with cottonseed protein concentrate. Moreover, the optimal level of dietary SAP supplementation for Pacific white shrimp could be inferred at $1.91 \%$. In this context, SAP can be considered as the potential improver for shrimp's low fishmeal feed.

\section{Data Availability}

All datasets generated for this study are included in the article/supplementary material. All raw data generated by the 
present gut microbiome were deposited in the Sequence Read Archive (SRA) of the National Center for Biotechnology Information (NCBI) under the registration number PRJNA741699. The sequencing data generated in this transcriptome study has been uploaded in the Genome Sequence Archive of the National Genomics Data Center (https://ngdc .cncb.ac.cn/), with the assigned accession number of CRA004649.

\section{Conflicts of Interest}

The authors declare that they have no competing interests.

\section{Authors' Contributions}

Hongyu Liu, Beiping Tan, Xiaohui Dong, Qihui Yang, and Shuyan Chi were involved in conceptualization; Guofeng Chen, Hongyu Liu, Shuang Zhang, and Min Yao designed the experiments; Baoqiang Liu and Jiajun Chen provided necessary experience assistance; Guofeng Chen was involved in data analysis and writing original draft; Guofeng Chen and Hongyu Liu reviewed and edited the manuscript. All authors approved the final version of the manuscript for submission.

\section{Acknowledgments}

This work was economically supported by the National Key R\&D Program of China (2019YFD0900200), National Natural Science Foundation of China (No. 31772864), Natural Science Foundation of Guangdong Province (2018A030313154 and 2020A1515011129), and Guangdong Enterprise Science and Technology Commissioner Project (GDKTP2020017800).

\section{References}

[1] L. H. Sun, W. J. Mao, H. W. Ji, S. C. Liu, J. Gao, and H. Y. Shao, "Effects of storage period and heating time on ATP-related compounds and quality changes in Litopenaeus vannamei," Journal of Guangdong Ocean University, vol. 40, no. 1, pp. 78-86, 2020.

[2] J. Min, X. Jia, Q. C. Zhou, Y. Ye, X. X. Wang, and S. Peng, "Dietary yeast hydrolysate and brewer's yeast supplementation could enhance growth performance, innate immunity capacity and ammonia nitrogen stress resistance ability of Pacific white shrimp (Litopenaeus vannamei)," Fish \& Shellfish Immunology, vol. 82, pp. 121-129, 2018.

[3] Q. Yu, Z. Fu, M. Huang, C. Xu, and E. Li, "Growth, physiological, biochemical, and molecular responses of Pacific white shrimp Litopenaeus vannamei fed different levels of dietary selenium," Aquaculture, vol. 535, p. 736393, 2021.

[4] R. Jannathulla, V. Rajaram, R. Kalanjiam, K. Ambasankar, M. Muralidhar, and J. S. Dayal, "Fishmeal availability in the scenarios of climate change: inevitability of fishmeal replacement in aquafeeds and approaches for the utilization of plant protein sources," Aquaculture Research, vol. 50, no. 12, pp. 3493-3506, 2019.

[5] R. L. Olsen and M. R. Hasan, "A limited supply of fishmeal: impact on future increases in global aquaculture production,"
Trends in Food Science \& Technology, vol. 27, pp. 120-128, 2012.

[6] Fisheries \& Fao AD, The state of world fisheries and aquaculture 2012, State of World Fisheries and Aquaculture (FAO), 2014.

[7] S. Maiolo, G. Parisi, N. Biondi, F. Lunelli, and R. Pastres, "Fishmeal partial substitution within aquafeed formulations: life cycle assessment of four alternative protein sources," The International Journal of Life Cycle Assessment, vol. 17, 2020.

[8] B. A. Sitjà, L. S. PeA, R. P. Gómez, F. Médale, S. Kaushik, and S. J. Pérez, "Effect of fish meal replacement by plant protein sources on non-specific defence mechanisms and oxidative stress in gilthead sea bream (Sparus aurata)," Aquaculture, vol. 249, pp. 387-400, 2005.

[9] B. E. Torstensen, M. Espe, M. Sanden et al., "Novel production of Atlantic salmon (Salmo salar) protein based on combined replacement of fish meal and fish oil with plant meal and vegetable oil blends," Aquaculture, vol. 285, pp. 193-200, 2008.

[10] J. Pratoomyot, E. Bendiksen, J. G. Bell, and D. R. Tocher, "Effects of increasing replacement of dietary fishmeal with plant protein sources on growth performance and body lipid composition of Atlantic salmon (Salmo salar L.)," Aquaculture, vol. 305, pp. 124-132, 2010.

[11] M. G. Wan, P. Yin, W. P. Fang, S. W. Xie, and J. S. Chen, "The effect of replacement of fishmeal by concentrated dephenolization cottonseed protein on the growth, body composition, haemolymph indexes and haematological enzyme activities of the Pacific white shrimp (Litopenaeus vannamei)," Aquaculture Nutrition, vol. 24, no. 6, pp. 1845-1854, 2018.

[12] S. W. Xie, Y. J. Liu, S. Zeng, J. Niu, and L. X. Tian, "Partial replacement of fish-meal by soy protein concentrate and soybean meal based protein blend for juvenile Pacific white shrimp, Litopenaeus vannamei," Aquaculture, vol. 464, pp. 296-302, 2016.

[13] L. Cruz Suárez, M. Nieto López, C. Guajardo Barbosa, M. Tapia Salazar, U. Scholz, and D. Ricque Marie, "Replacement of fish meal with poultry by-product meal in practical diets for Litopenaeus vannamei, and digestibility of the tested ingredients and diets," Aquaculture, vol. 272, pp. 466-476, 2007.

[14] M. Weiss, A. Rebelein, and M. J. Slater, "Lupin kernel meal as fishmeal replacement in formulated feeds for the Whiteleg shrimp (Litopenaeus vannamei)," Aquaculture Nutrition, vol. 26, no. 3, pp. 752-762, 2020.

[15] N. Bai, M. Gu, X. Xu, B. Xu, and Å. Krogdahl, "Protective effects of mannan oligosaccharides on turbot_Scophthalmus maximus_suffering from soy enteropathy," Aquaculture, vol. 476, no. 1, pp. 141-151, 2017.

[16] B. Yin, H. Liu, B. Tan et al., "Cottonseed protein concentrate (CPC) suppresses immune function in different intestinal segments of hybrid grouper oEpinephelusfuscoguttatus $\times{ }^{\star}$ Epinephelus. lanceolatu via TLR-2/MyD88 signaling pathways," Fish \& Shellfish Immunology, vol. 81, pp. 318-328, 2018.

[17] A. Gy, C. Xdab, C. Qyab et al., "Low-gossypol cottonseed protein concentrate used as a replacement of fish meal for juvenile hybrid grouper (Epinephelus fuscoguttatus $\$ \times$ Epinephelus lanceolatus ${ }^{\top}$ ): effects on growth performance, immune responses and intestinal microbiota," Aquaculture, vol. 524, p. 735309, 2020.

[18] J. Shen, H. Liu, B. Tan et al., "Effects of replacement of fishmeal with cottonseed protein concentrate on the growth, intestinal microflora, haematological and antioxidant indices of juvenile 
golden pompano (Trachinotus ovatus)," Aquaculture Nutrition, vol. 26, no. 4, pp. 1119-1130, 2020.

[19] Y. Cai, D. C. Liu, X. L. Wang, R. J. Chen, J. H. Xie, and J. Y. Wu, "Effect of temperature, illuminance and nitrogen-phosphorus ratio on selenium enrichment in Caulerpa lentillifera," Journal of Guangdong Ocean University, vol. 39, no. 3, pp. 46-53, 2019.

[20] V. Jayachandran, A. Sukumaran, K. Se-Kwon, and S. Min, "Seaweed polysaccharide-based nanoparticles: preparation and applications for drug delivery," Polymers, vol. 8, pp. 125, 2016.

[21] W. Chotigeat, S. Tongsupa, K. Supamataya, and A. Phongdara, "Effect of fucoidan on disease resistance of black tiger shrimp," Aquaculture, vol. 233, pp. 23-30, 2004.

[22] K. Supamattaya, S. Kiriratnikom, M. Boonyaratpalin, and L. Borowitzka, "Effect of a Dunaliella extract on growth performance, health condition, immune response and disease resistance in black tiger shrimp (Penaeus monodon)," Aquaculture, vol. 248, pp. 207-216, 2005.

[23] Z. L. Han, M. Yang, X. Fu et al., "Evaluation of prebiotic potential of three marine algae oligosaccharides from enzymatic hydrolysis," Marine Drugs, vol. 17, no. 3, p. 173, 2019.

[24] B. Wcl, A. Shz, C. Bb, A. Fyz, A. Cbs, and E. Hypad, "Dietary seaweed (Enteromorpha) polysaccharides improves growth performance involved in regulation of immune responses, intestinal morphology and microbial community in banana shrimp Fenneropenaeus merguiensis," Fish \& Shellish Immunology, vol. 104, pp. 202-212, 2020.

[25] C. L. Okolie, S. Rajendran, C. C. Udenigwe, A. Aryee, and B. Mason, "Prospects of brown seaweed polysaccharides (BSP) as prebiotics and potential immunomodulators," Journal of Food Biochemistry, vol. 41, no. 5, article e12392, 2017.

[26] V. Raguraman, N. Ravindran, K. Selvaraju, and G. Kasivelu, "Seaweed polysaccharides as potential therapeutic agents against white spot syndrome virus (WSSV): a mini review," Aquaculture International, vol. 28, pp. 1-11, 2020.

[27] Z. H. Duan, L. N. Jiang, J. L. Wang, X. Y. Yu, and T. Wang, "Drying and quality characteristics of tilapia fish fillets dried with hot air-microwave heating," Food and Bioproducts Processing, vol. 89, pp. 472-476, 2011.

[28] G. W. Ray, D. Liang, Q. Yang et al., "Effects of replacing fishmeal with dietary soybean protein concentrate (SPC) on growth, serum biochemical indices, and antioxidative functions for juvenile shrimp Litopenaeus vannamei," Aquaculture, vol. 516, p. 734630, 2020.

[29] S. Ayiku, J. Shen, B. P. Tan, X. H. Dong, and H. Y. Liu, "Effects of dietary yeast culture on shrimp growth, immune response, intestinal health and disease resistance against Vibrio harveyi," Fish \& Shellfish Immunology, vol. 102, pp. 286-295, 2020.

[30] R. C. Edgar, "UPARSE: highly accurate OTU sequences from microbial amplicon reads," Nature Methods, vol. 10, p. 996, 2013.

[31] N. A. Bokulich, S. Subramanian, J. J. Faith et al., "Quality-filtering vastly improves diversity estimates from Illumina amplicon sequencing," Nature Methods, vol. 10, pp. 57-59, 2013.

[32] Q. Y. Zhao, Y. Wang, Y. M. Kong, D. Luo, X. Li, and P. Hao, "Optimizing de novo transcriptome assembly from shortread RNA-Seq data: a comparative study," BMC Bioinformatics, vol. 12, no. 14, pp. 1-12, 2011.

[33] P. Geo, X. Huang, F. Liang et al., "TIGR gene indices clustering tools (TGICL): a software system for fast clustering of large EST datasets," Bioinformatics, vol. 19, pp. 651-652, 2003.
[34] G. Stefan, G. Miguel, T. Javier et al., "High-throughput functional annotation and data mining with the Blast2GO suite," Nucleic Acids Research, vol. 36, pp. 3420-3435, 2008.

[35] B. Langmead and S. L. Salzberg, "Fast gapped-read alignment with Bowtie 2," Nature Methods, vol. 9, pp. 357-359, 2012.

[36] C. N. Dewey and B. Li, "RSEM: accurate transcript quantification from RNA-Seq data with or without a reference genome," BMC Bioinformatics, vol. 12, pp. 323-323, 2011.

[37] A. Mortazavi, B. A. Williams, K. Mccue, L. Schaeffer, and B. Wold, "Mapping and quantifying mammalian transcriptomes by RNA-Seq," Nature Methods, vol. 5, no. 7, pp. 621628, 2008.

[38] G. K. Smyth, "edgeR: a Bioconductor package for differential expression analysis of digital gene expression data," Bioinformatics, vol. 26, no. 1, p. 139, 2010.

[39] G. P. Vieira, I. R. C. B. Rocha, F. Costa, and B. G. Rádis, "Differential induction of HSP-70 expression in response to IHHNV in white shrimp Litopenaeus vannamei naturally coinfected with IHHNV and IMNV," International Aquatic Research, vol. 4, no. 1, pp. 1-13, 2012.

[40] R. Du, L. Xia, X. Ning et al., "Hypoxia-induced Bmi 1 promotes renal tubular epithelial cell-mesenchymal transition and renal fibrosis via PI3K/Akt signal," Molecular Biology of the Cell, vol. 25, pp. 2650-2659, 2014.

[41] H. Abe, "Distribution, metabolism and physiological functions of free d-amino acids in aquatic invertebrates (review paper)," Nippon Suisan Gakkaishi, vol. 68, pp. 516-525, 2002.

[42] Y. J. Choi, S. R. Lee, and J. W. Oh, "Effects of dietary fermented seaweed and seaweed fusiforme on growth performance, carcass parameters and immunoglobulin concentration in broiler chicks," Asian-Australasian Journal of Animal Sciences, vol. 27, pp. 862-870, 2014.

[43] S. F. Zhao, H. Q. Sun, D. Wang, and P. M. He, "Nutrient components analysis of eight kinds of seaweeds in Zhanjiang sea area," Journal of Guangdong Ocean University, vol. 28, no. 6, pp. 30-34, 2008.

[44] M. M. Islam, S. T. Ahmed, H. S. Mun, Y. B. Kim, and C. J. Yang, "Effect of fermented seaweed by-product supplementation on reproduction of Hanwoo cows and growth and immunity of their calves," Animal Production Science, vol. 56, pp. 1828-1833, 2015.

[45] S. I. Mussatto and I. M. Mancilha, "Non-digestible oligosaccharides: a review," Carbohydrate Polymers, vol. 68, pp. 587597, 2007.

[46] G. Chen, B. Yin, H. Liu et al., "Supplementing chitosan oligosaccharide positively affects hybrid grouper (Epinephelus fuscoguttatus $\$ \times$ E. lanceolatus $\left.\delta^{\star}\right)$ fed dietary fish meal replacement with cottonseed protein concentrate: effects on growth, gut microbiota, antioxidant function and immune response," Frontiers in Marine Science, vol. 8, p. 707627, 2021.

[47] Y. Chen, S. Chi, S. Zhang et al., "Replacement of fish meal with Methanotroph (Methylococcus capsulatus, Bath) bacteria meal in the diets of Pacific white shrimp (Litopenaeus vannamei)," Aquaculture, vol. 541, p. 736801, 2021.

[48] D. Scibior and H. Czeczot, "Catalase: structure, properties, functions," Postępy Higieny i Medycyny Doświadczalnej, vol. 60, no. 2-3, pp. 170-180, 2006.

[49] N. Nuntapong, W. Ph Romkunthong, S. Wanlem, and M. Boonyaratpalin, "Dietary exposure to melamine and cyanuric acid induced growth reduction, oxidative stress and pathological changes of hepatopancreas in Pacific white 
shrimp," International Aquatic Research, vol. 11, no. 1, pp. 1331, 2019.

[50] R. Agregan, P. E. Munekata, D. Franco, R. Dominguez, J. Carballo, and J. M. Lorenzo, "Phenolic compounds from three brown seaweed species using LC-DAD-ESI-MS/MS," Food Research International, vol. 99, pp. 979-985, 2017.

[51] S. M. Ahn, Y. K. Hong, G. S. Kwon, and H. Y. Sohn, "Evaluation of antioxidant and nitrite scavenging activity of seaweed extracts," Journal of Life Science, vol. 21, pp. 576-583, 2011.

[52] X. T. Ma, X. Y. Sun, K. Yu, B. S. Gui, Q. Gui, and J. M. Ouyang, "Effect of content of sulfate groups in seaweed polysaccharides on antioxidant activity and repair effect of subcellular organelles in injured HK-2 cells," Oxidative Medicine and Cellular Longevity, vol. 2017, Article ID 2542950, 13 pages, 2017.

[53] M. Maryam, S. Mehdi, S. Ali, H. Pezhman, S. M. Mehdi, and L. Alan, "Effect of date palm (Phoenix dactylifera) seed extract as a dietary supplementation on growth performance immunological haematological biochemical parameters of common carp," Aquaculture Research, vol. 49, pp. 2903-2912, 2018.

[54] B. Yin, H. Liu, B. Tan et al., "Preliminary study of mechanisms of intestinal inflammation induced by plant proteins in juvenile hybrid groupers (올 Epinephelus fuscoguttatus $\times{ }^{\top}$ E. lanceolatu)," Fish \& Shellfish Immunology, vol. 106, pp. 341-356, 2020.

[55] J. Bae, A. Hamidoghli, M. S. Djaballah et al., "Effects of three different dietary plant protein sources as fishmeal replacers in juvenile whiteleg shrimp, Litopenaeus vannamei," Fisheries and Aquatic Science, vol. 23, no. 1, 2020.

[56] R. Ghoshal and N. P. S. Hu, "Expression of TLR-22 gene and response of non specific immunity of Labeo rohita fed with fucoidan rich seaweed extract in conjugation with Bacillus subtilis," International Journal of Current Microbiology and Applied Sciences, vol. 8, no. 11, pp. 347-361, 2019.

[57] M. Yang, Z. Lu, F. Li et al., “Alginate oligosaccharide improves fat metabolism and antioxidant capacity in the liver of grass carp (Ctenopharyngodon idellus)," Aquaculture, vol. 540, p. $736664,2021$.

[58] G. Chen, B. Yin, H. Liu et al., "Effects of fishmeal replacement with cottonseed protein concentrate on growth, digestive proteinase, intestinal morphology and microflora in pearl gentian grouper (ㅇ Epinephelus fuscoguttatus $\times$ ơ Epinephelus lanceolatu)," Aquaculture Research, vol. 51, pp. 2870-2884, 2020.

[59] E. Santigosa, J. Sánchez, F. Médale, S. Kaushik, J. Pérez-Sánchez, and M. A. Gallardo, "Modifications of digestive enzymes in trout (Oncorhynchus mykiss) and sea bream (Sparus aurata) in response to dietary fish meal replacement by plant protein sources," Aquaculture, vol. 282, pp. 68-74, 2008.

[60] D. Hernández, J. Santinón, S. Sánchez, and H. A. Domitrovic, "Dietary soybean meal on growth and intestinal morphology of South American catfish, Rhamdia quelen, larvae," Ciência Rural, vol. 42, pp. 1662-1668, 2012.

[61] J. Wan, J. Zhang, D. Chen, B. Yu, and J. He, "Effects of alginate oligosaccharide on the growth performance, antioxidant capacity and intestinal digestion-absorption function in weaned pigs," Animal Feed Science and Technology, vol. 234, pp. 118-127, 2017.

[62] P. Zhang, J. Liu, B. Xiong, C. Zhang, and H. Zhang, "Microbiota from alginate oligosaccharide-dosed mice successfully mitigated small intestinal mucositis," Microbiome, vol. 8, no. 1, pp. 1-15, 2020.

[63] Y. Zhao, Y. Feng, M. Liu, L. Chen, and H. Zhang, "Single-cell RNA sequencing analysis reveals alginate oligosaccharides preventing chemotherapy-induced mucositis," Mucosal Immunology, vol. 13, pp. 1-12, 2020.

[64] L. Baldo, J. L. Riera, K. D. R. A. Tooming, M. Albà, and W. Salzburger, "Gut microbiota dynamics during dietary shift in eastern African cichlid fishes," PLoS One, vol. 10, 2015.

[65] K. Yukgehnaish, P. Kumar, P. Sivachandran, K. Marimuthu, and J. Arockiaraj, "Gut microbiota metagenomics in aquaculture: factors influencing gut microbiome and its physiological role in fish," Reviews in Aquaculture, vol. 12, no. 3, pp. 19031927, 2020.

[66] S. Otles, Aquaculture nutrition: gut health, probiotics and prebiotics, Houghton Mifflin Riverside Press, 2014.

[67] J. Tiede, C. Scherber, J. Mutschler, K. D. Mcmahon, and C. Gratton, "Gut microbiomes of mobile predators vary with landscape context and species identity," Ecology and Evolution, vol. 7, no. 20, pp. 8545-8557, 2017.

[68] J. Yano, K. Yu, G. Donaldson et al., "Indigenous bacteria from the gut microbiota regulate host serotonin biosynthesis," Cell, vol. 161, pp. 264-276, 2015.

[69] S. V. Hindu, N. Chandrasekaran, A. Mukherjee, and J. Thomas, "A review on the impact of seaweed polysaccharide on the growth of probiotic bacteria and its application in aquaculture," Aquaculture International, vol. 27, pp. 227-238, 2019.

[70] J. Niu, J. J. Xie, T. Y. Guo et al., "Comparison and evaluation of four species of macro-algaes as dietary ingredients in Litopenaeus vannamei under normal rearing and WSSV challenge conditions: effect on growth, immune response, and intestinal microbiota," Frontiers in Physiology, vol. 9, p. 1880, 2019.

[71] Z. Ju, A. Karsi, A. Kocabas et al., "Transcriptome analysis of channel catfish (Ictalurus punctatus): genes and expression profile from the brain," Gene, vol. 261, pp. 373-382, 2000.

[72] C. Schunter, S. V. Vollmer, E. Macpherson, and M. Pascual, "Transcriptome analyses and differential gene expression in a non-model fish species with alternative mating tactics," BMC Genomics, vol. 15, no. 1, pp. 1-14, 2014.

[73] Y. Zhang, G. Gao, R. Lin, J. J. Aweya, M. Tao, and W. Fan, "Transcriptome analyses reveal Litopenaeus vannamei hemocytes response to lipopolysaccharide," Fish \& Shellfish Immunology, vol. 76, pp. 187-195, 2018.

[74] J. A. Calduch Giner, A. Bermejo Nogales, L. Benedito Palos, I. Estensoro, and J. Pérez-Sánchez, "Deep sequencing for de novo construction of a marine fish (Sparus aurata) transcriptome database with a large coverage of protein-coding transcripts," BMC Genomics, vol. 14, pp. 178-178, 2013.

[75] D. Zhang, P. Zhao, J. Liu et al., “Transcriptome analysis reveals the tolerance mechanism of mantis shrimp (Oratosquilla oratoria) under a lipopolysaccharide challenge," ACS Omega, vol. 5, pp. 2310-2317, 2020.

[76] W. Zhang, K. Liu, B. Tan et al., "Transcriptome, enzyme activity and histopathology analysis reveal the effects of dietary carbohydrate on glycometabolism in juvenile largemouth bass, Micropterus salmoides," Aquaculture, vol. 504, pp. 39-51, 2019.

[77] L. S. Yang, Z. X. Yin, J. X. Liao, X. D. Huang, and J. G. He, “A Toll receptor in shrimp," Molecular Immunology, vol. 44, pp. 1999-2008, 2007.

[78] M. M. Dechamma, M. K. Mani, M. Rajeish et al., "Differential expression of akirin gene in black tiger shrimp Penaeus monodon in response to immunostimulant administration and infections with Vibrio harveyi and white spot syndrome virus," 
Journal of the World Aquaculture Society, vol. 51, pp. 10541065, 2020.

[79] A. Deepika, K. Sreedharan, A. Paria, M. Makesh, and K. V. Rajendran, "Toll-pathway in tiger shrimp (Penaeus monodon) responds to white spot syndrome virus infection: evidence through molecular characterisation and expression profiles of MyD88, TRAF6 and TLR genes," Fish \& Shellfish Immunology, vol. 41, pp. 441-454, 2014.

[80] J. Zhao, Y. Han, Z. Wang, R. Zhang, G. Wang, and Y. Mao, "Alginate oligosaccharide protects endothelial cells against oxidative stress injury via integrin- $\alpha / F A K / P I 3 K$ signaling," Biotechnology Letters, vol. 42, pp. 2749-2758, 2020.

[81] J. Zhou, W. N. Wang, W. Y. He et al., "Expression of HSP60 and HSP70 in white shrimp, Litopenaeus vannamei in response to bacterial challenge," Journal of Invertebrate Pathology, vol. 103, pp. 170-178, 2010.

[82] P. Yarahmadi, H. G. Farsani, A. Khazaei, M. Khodadadi, G. Rashidiyan, and M. A. Jalali, "Protective effects of the prebiotic on the immunological indicators of rainbow trout (Oncorhynchus mykiss) infected with Aeromonas hydrophila," Fish \& Shellfish Immunology, vol. 54, pp. 589-597, 2016. 